\title{
Ueber das letzte Glied der Beine bei den Arthropoden.
}

\author{
Von \\ Dr. J. C. H. de Meijere in Amsterdam.
}

Hierzu Tafel $30-37$.

Obgleich die Literatur über die Endapparate am Beine, namentlich der Insecten, keine dürftige ist, so beziehen sich doch die meisten der hierbei in Betracht kommenden Arbeiten mehr auf die Physiologie, den Gebrauch dieser Theile, während die Anatomie nur in so fern berücksichtigt wurde, als dieselbe für das Verständniss ihrer Function der Untersuchung werth schien. Es hatten diese Untersuchungen nämlich in der Regel das Ziel, Aufschlüsse zu geben über die Weise, wie sich die Insecten dieses Endtheils der Beine beim Laufen oder Klettern bedienen. Eine ausführlichere vergleichend-anatomische Untersuchung von diesem Theil des Insecten- oder überhaupt des Arthropodenkörpers liegt meines Wissens noch nicht vor. Das erklärt zunächst die sehr verschiedene Auffassung, welche man über diese Theile in den Handbüchern z. B. antrifft. Was die Insecten anlangt, so wird meistens angenommen, dass sich am letzten Tarsengliede, das hier meistens das 5. ist, verschiedene Anhänge befinden, welche nach Form und Function als Krallen, Haftläppchen u. s. w. unterschieden werden. Namentlich sollen die Krallen die Bedeutung modificirter Borsten oder Haare haben.

Diese Auffassung findet sich z. B. in den allerneuesten Handbüchern der hervorragenden Zoologen SHARP ${ }^{1}$ ) und PACKARD ${ }^{2}$ ) vertreten. Dieselbe Meinung vertheidigt Pagenstecher in seinem Handbuch "Allgemeine Zoologie", auch was die Arachniden anlangt.

1) Sharp, Insects, V. 1, p. 105, in: Cambridge natural History.

2) Packard, A textbook of entomology, 1898, p. 96. 
Doch hat man schon seit längerer Zeit auch andern Auffassungen gehuldigt. Schon Réaumur hat in seinen Mémoires ${ }^{1}$ ) darauf hingewiesen, dass bei Apis mellifica L. etwa ein 6. Tarsalglied vorkommt, welches die Krallen und das stark entwickelte Luftkissen trägt.

Bei mehreren Autoren späterer Zeit findet sich dieselbe Auffassung, so z. B. in den Arbeiten von Pokorsky ${ }^{2}$ ) und von Tuffen WEST $^{3}{ }^{3}$. Dieser Autor hat nicht nur bei denjenigen Insecten, welche einen unpaarigen Haftlappen besitzen, diese Annahme vertheidigt, sondern auch bei den mit 2 Haftlappen versehenen Fliegen. Er deutete diese als ein tief eingeschnittenes Glied, welches mit den tief zweilappigen Tarsalgliedern von Curculio und Chrysomela ${ }^{4}$ ) zu vergleichen wäre. Die Krallen betrachtet er jedoch immer als modificirte Haare ,,converted into hooks to serve a special purpose“. An anderer Stelle heisst es: "The sustentacula" (d. h. die krallenähnlichen Borsten am Ende des Tarsus) ,of Epeira, the analogous structures on the entire under surface of the last tarsal joints in Pholcus, the condition of the parts in the hind limbs of Notonecta in both is mature and earlier condition, as well as in Sarcoptes, Psoroptes and some other Acari, all contribute to the proof of this fact" ${ }^{\text {5) }}$.

Keine geringere Autorität als HuXLEy hat sich in derselben Weise ausgelassen. In seinem Handbuch der Anatomie der wirbellosen Thiere findet sich in einer Anmerkung die Meinung, dass der sogenannte Pulvillus von Blatta als 6 . Glied aufgefasst werden müsse. In dem bekannten Buch: „The Cockroach" von Miall u. Denny ${ }^{6}$ ) haben diese Autoren die Bemerkung HuxLeY's wiederholt und dieselbe wenigstens nicht zurückgewiesen.

Ueber die Krallen selbst finden sich hier und dort auch schon andere Ansichten. So sagt Sundevall ${ }^{7}$ ), indem er über Fälle spricht,

1) Mémoires pour servir à l'histoire des Insectes, V. 5, Mém. 6, p. 291 (édit. in $4^{0}$, Paris 1740).

2) A. von Pokonsky Joravko, Quelques remarques sur le dernier article du tarse des Hyménoptères, in: Bull. Soc. Imp. Nat. Moscou, 1844, V. 17 , p. $149-159$.

3) On the foot of the fly, in: Trans. Linn. Soc. London, V. 23, 1862 , p. 393.

4) in: Journ. Proc. Linn. Soc. London, V. 6, p. 27.

5) On the foot of the fly, in: Trans. Linn. Soc. London, V. 23, 1862 , p. 417.

6) The structure and life history of the Cockroach, 1886, p. 61.

7) Om Insekternas Extremiteter etc., in: Svensk. Ved. Akad. Handl., V. 3,1860 , p. 6 . 
wo der Fuss bei einem Insect mit ein er Kralle enden soll, dass dieselbe hier wohl eher als das 6. Tarsalglied $\mathrm{zu}$ deuten wäre. Auch MeINert scheint in einer neuern Arbeit über Pycnogoniden ${ }^{1}$ ) derselben Meinung zugethan, indem er einen Unterschied macht zwischen zwei- und einkralligen Füssen und in letztern Fällen eine Homologie zwischen dieser Kralle und dem klauenförmigen Endglied (,the last, terminal joint of the leg) der Pycnogoniden annimmt.

Milne-EdwaRds ${ }^{2}$ ) behauptet über die Krallen der Insecten im Allgemeinen, dass dieselben mit den Dactylopoditen der Crustaceen zu vergleichen seien (,le dernier article du tarse donne insertion à une paire de crochets comparables aux dactylopodites des Crustacés").

In den neuern Arbeiten über Insectenfüsse, wobei zunächst der Abhandlungen von Dewitz ${ }^{3}$ ), DAHL ${ }^{4}$ ) und OCKLeR ${ }^{5}$ ) zu gedenken ist, ist in so fern ein Rückschritt erkennbar, als die Theorie des 6. Tarsalgliedes hierin wieder zurückgewiesen oder wenigstens dieselbe als etwas ganz Gleichgültiges betrachtet wird. Namentlich DAHL hat sich in dieser Hinsicht bestimmt ausgesprochen, indem er sagt: „Einige Autoren haben aus den 5 Gliedern 6 machen wollen, indem sie die Krallen mit den oft dazwischen befindlichen Haftorganen als besonderes Glied ansahen. Dahinzu müsste man dann wohl die später zu betrachtende Streckplatte nehmen. Diese Annahme kann auch vollkommen zugegeben werden, man müsste nur den Begriff eines Tarsengliedes etwas weiter fassen. Im Ganzen ist es indessen doch vollkommen gleichgültig, ob man sich dieser oder jener Ansicht zuneigt, und mit Gründen, die man für die eine oder andere beibringt, ist im Grunde genommen nichts gewonnen. Genetisch sind entschieden die Krallen als bewegliche Haare oder Borsten aufzufassen und vielleicht auch die Haftläppchen."

Gerade letztere Behauptung, welcher ich durchaus nicht zustimmen kann, deutet darauf hin, dass es doch noch nicht so sehr überflüssig ist, die morphologische Seite der Sache so genau wie mög-

1) in: The Danish Ingolf Expedition, V. 3, 1899, p. 9.

2) Leçons sur la physiologie et l'anatomie comparée, V. 10, 1872, p. 243.

3) Ueber die Fortbewegung der Thiere an senkrechten, glatten Flächen vermittelst eines Secrets, in: Arch. ges. Physiol., V. 33, 1884, p. 440; nebst mehreren kleinern Abhandlungen.

4) Beiträge zur Kenntniss des Baues der Functionen der Insectenbeine, in: Arch. Naturg., Jg. 50, V. 1, 1884, p. 146.

5) Das Krallenglied am Insectenfuss, ibid. Jg. 56, V. 1, 1890, p. 221. 
lich zu erforschen, auch wenn es für das Verständniss der Function vollkommen gleichgültig wäre, welcher Auffassung man sich zuneigt.

Die Tabelle von den Haftapparaten, welche sich auf p. 178 der erwähnten $\mathrm{D}_{\mathrm{AHL}}$ 'schen Arbeit findet, hat denn auch gar keinen weitern morphogenetischen Werth. Es werden hierin folgende Fälle unterschieden :

A. Haftapparate an der Fussohle:

a) ohne Hafthaare (Orthoptera);

b) mit Hafthaaren (Forficula, Coleoptera, Sialis).

B. Haftapparate zwischen den Krallen.

a) mit mittlerm Haftlappen: $\alpha$ ) mittlerer Haftlappen mit Chitinbogen (1 mit Nebenläppchen, N europtera; 2 ohne Nebenläppchen, Hymenoptera); $\beta$ ) mittlerer Haftlappen ohne Chitinbogen (Lepidoptera, Tipula); b) kein ungepaarter Haftlappen: 1 Haftlappen behaart (Di ptera); 2 Haftlappen unbehaart (Hemiptera).

Es ist einigermaassen schwer, aus der Arbeit OCKLER's, der wohl am ausführlichsten die distalen Enden vieler Insectenbeine untersuchte, zu entnehmen, welche Ansicht dieser Autor in der uns beschäftigenden Frage hegt. Derselbe hebt allerdings ein „Krallenglied" gegenüber dem Tarsenendglied hervor, doch scheint er mir ersteres nur als ganz secundäre Sprosse des letztern aufzufassen, indem er z. B. auf p. 231 anführt: „Wie das ganze Bein für eine Ausstülpung vom Stamm erachtet wird, so halte ich die Haftläppchen genetisch ebenfalls nur für eine umgewandelte Ausstülpung der das Tarsenglied abschliessenden und mit den Krallen verbindenden Haut." Auch ist es mir unklar, wo er die Grenze zwischen Tarsenendglied und Krallenglied zieht, da von ihm wenigstens noch die später $\mathrm{zu}$ betrachtende Streckplatte als zum Tarsenendglied gehörig aufgefasst wird. Es bleibt dann aber für das Krallenglied nicht viel übrig, um so mehr, als er die Krallen selbst als "für bestimmte Zwecke modificirte Borsten" betrachtet haben will. Dennoch berichtet er selbst auf p. 228, dass die Krallen „die Matrix enthalten“, was mit dieser Ansicht sogleich im Widerspruch steht, wenn man wenigstens den Unterschied versteht zwischen Borste und borstenähnlichem Fortsatz. Der Name „Krallenglied" scheint mir überhaupt unzweckmässig, da hiermit nur zu oft das letzte Tarsenglied selbst bezeichnet wird, so z. B. in dem bekannten KoLBE'schen Buche: „Einführung in die Kenntniss der Insecten". Daselbst findet sich über die Endapparate der Insectenbeine eine Ansicht, welche mir den wirklichen Verhältnissen besser 
zu entsprechen scheint als die Mittheilungen der meisten andern Forscher. Es heisst daselbst auf p. 283: „Die Krallen sind an der Oberseite eines sehr kleinen selbständigen Gliedes (Afterglied) eingefügt, welches am Grunde kräftig gebaut, stark chitinisirt und nach vorn meist verlängert ist, um das zwischen den beiden Krallen sichtbare, für viele Insecten wichtige Haftläppchen oder die Afterkralle zu bilden." Doch lässt der Autor auf der folgenden Seite wieder mit OcKLER die Haftläppchen durch Ausstülpung des Krallengliedes (d. h. ihres Tarsenendgliedes) entstehen. In Uebereinstimmung hiermit wird auf p. 278 die Zahl der Fussglieder als höchstens 5 angegeben.

Bei diesem Stande der Frage schien es mir nicht überflüssig, eine grössere Anzahl Vertreter der verschiedenen Arthropodengruppen auf diesen Punkt hin zu untersuchen und die verschiedenen Befunde mit einander zu vergleichen. Bei der ungeheuren Menge von Angehörigen dieser Thiergruppe muss die Zahl der untersuchten Formen jedoch immerhin eine relativ geringe bleiben, und ich bin mir wohl bewusst, dass sehr interessante Fälle mir entgangen sein werden. Es lässt sich dies um so eher behaupten, als innerhalb kleiner Abtheilungen das Verhalten oft noch überaus verschiedenartig sein kann. In der sehr ausgedehnten systematischen Literatur finden sich auch mehrmals Angaben über das Ende der Füsse. In der Regel haben sich die Autoren jedoch hier nicht auf solche Einzelheiten eingelassen, dass die Sache für unser Thema genügend behandelt ist. Es wäre natürlich ganz unmöglich, alle die bezüglichen Angaben aufzuspüren und richtig zu würdigen; ich habe dieselben nur gelegentlich erwähnt, wo sie mir noch bedeutenderes Interesse $\mathrm{zu}$ haben sciiienen.

Ehe ich nun die von mir untersuchten Fälle in systematischer Anordnung anführe, scheint es mir wünschenswerth, zunächst in Kurzem ein paar Fälle näher zu beschreiben, zur Erörterung der gebrauchten Termini, welche meistens von DAHL und Ockler eingeführt wurden.

Zunächst möge hier als Beispiel eines einkralligen Fusses Pediculus (Fig. 24) behandelt werden. Wir unterscheiden hier an dieser Kralle einen obern und einen untern Rand; der untere ist proximalwärts durch eine membranöse Strecke (die Strecksohle, OckLER) von einer mit besonders dicker Chitinschicht bedeckten, schuppig befelderten Partie (der Streckplatte, DAHL) getrennt. Bei der Bewegung der Kralle gleitet diese Streckplatte über den ebenfalls stark verdickten, nach innen umgebogenen Fortsatz der Ventralseite des letzten Tarsalgliedes hinweg. Letztere verdickte Stelle trägt den Nàmen Gleitfläche. 
Ausser diesen beiden untern Gelenkflächen finden wir zwei eben solche an der Oberseite. Es wird hier das Gelenk einerseits durch das obere Ende der Kralle selbst, andrerseits durch einen besondern Höcker (den Gelenkhöcker) am letzten Tarsalglied gebildet. Letzterer ist ein nach vorn vorspringender Fortsatz am obern Ende des betreffenden Gliedes. Die Sehne des einzigen Muskels, welche hier wie bei allen Insecten die Bewegung der Krallen bewerkstelligt, ist mit dem proximalen Ende der Streckplatte verbunden. Beim Zusammenziehen des Muskels wird also die Kralle gebogen; zur Streckung der Kralle genügt die eigene Elasticität der verschiedenen Theile ${ }^{1}$ ). Die genannte Sehne durchzieht alle Fussglieder und die Schiene und geht erst im Schenkel in einen am Grunde des Schenkels angehefteten Muskel über (KOLBE).

Wo, wie in Fig. 11 von Periplaneta americana, 2 Krallen vorhanden sind, thun dieselben sich bei genauerer Betrachtung als Anhänge einer unpaarigen Medianpartie des Endapparats dar. An letzterer findet sich unterseits, wie im vorigen Falle, die Streckplatte, und auch die Gleitfläche ist an der entsprechenden Stelle vorhanden. Die Oberseite dieser Partie geht aber als eine dünne Membran in die Oberseite des letzten Tarsalgliedes über. Der Gelenkhöcker an letzterm ist hier am Ende gegabelt, wodurch für je eine Kralle eine Gelenkfläche gebildet wird.

Ein medianer Längsschnitt (Fig. 12) trifft hier also nicht die Krallen selbst, sondern die dünne Membran, welche die Oberseite der genannten Medianpartie bildet. Nur ausnahmsweise kommen hierin stärker chitinisirte Stellen vor, so z. B. namentlich bei mehreren Hymenopteren. Die Medianpartie setzt sich distalwärts sehr oft in ein sehr verschiedenartiges Gebilde fort, namentlich oft in ein als Haftapparat fungirendes Kissen. Von den verschiedenen Namen, mit denen dieser Fortsatz bezeichnet wird, wie Empodium, Pulvillus, Arolium, Palmula, Plantula, Onychium u. s. w., scheint mir der Name Emp odium, als wenig präjudicirender, der zweckmässigste zu sein. Die Function dieses Empodiums kann sehr verschiedenartig sein. Zwischen Streckplatte und Empodium findet sich wieder die Strecksohle, zu beiden Seiten der Medianpartie kommt oft je ein lappenförmiger Anhang vor, welche beide auch vielfach als Haftapparate von Nutzen sind. Diese, als Pulvilli, Arolia u. s. w. unterschiedenen Gebilde

1) Ich muss hier darauf hinweisen, dass in Packard's Textbook of Entomology in fig. 233 noch die namentlich mit Hinsicht auf die Krallenbewegung unrichtige Abbildung von Straus-Dürkheim angetroffen wird, Es giebt eben keinen "Extensor" der Kralle. 
schlage ich vor einstweilen als Seitenläppchen (Lobuli laterales) zu bezeichnen.

Obgleich ich erst nach Mittheilung der Befunde selbst die Begründung für diese Ansicht geben werde, will ich hier gleich bemerken, dass die Medianpartie mit ihren Anhängen von mir als besonderes Glied betrachtet wird, für welches ich den Namen Praetarsus vorschlage. Der gebräuchliche Terminus Metatarsus für das auf die Schiene folgende Tarsalglied lässt das Prädicat prae oder pro gewünscht erscheinen. Ich habe „Praetarsus“ gewählt, weil der Name Protarsus nach Analogie mit Prothorax eher dem letzten Tarsalglied selbst zukommen möchte. Ueberdies wird der Name Protarsus schon für das proximale Tarsalglied der Arachniden gebraucht. Das Endglied betrachte ich, wie weiter unten dargelegt werden wird, nicht einmal als einen Abschnitt des Tarsus, sondern als ganz selbständige Beinabtheilung.

Es möge jetzt die Darlegung meiner Befunde folgen.

Die Thysanura zeigen den Praetarsus schon ganz deutlich und von gewöhnlicher Bildung. Die Streckplatte ist namentlich bei Lepisma (Fig. 1,2) stark entwickelt und fällt durch ihre gelbe Farbe sehr in die Augen. Auch der Gelenkhöcker ist vorhanden. Das Empodium ist bei Lepisma krallenartig und articulirt auch mit dem Gelenkhöcker. Bei Campodea.(Fig. 3) ist alles viel zarter, und das Empodium fehlt, dagegen findet sich hier vor der Wurzel der Krallen jederseits ein feines Haar, welches schon von MernerT angegeben wurde ${ }^{1}$ ). Dieses Haar sitzt eben an der Stelle, wo sonst oft die Seitenläppchen zu finden sind, so dass es vielleicht als Homologon von diesen Organen zu betrachten ist, welche Auffassung noch dadurch gestützt wird, das bei einer ostindischen Thysanure (Lepidocampa weberi Oudem.) nach Oudemans ${ }^{2}$ ) jederseits ein borstiges Organ nachweisbar ist, „,welches in der Gestalt einigermaassen mit Weidenkätzchen zu vergleichen ist. Jede einzelne Borste eines solchen Organs hat eine etwas angeschwollene Spitze“.

Nach Grassi finden sich bei Nicoletia 3 Krallen; es besteht hier also wohl dasselbe Verhalten wie bei Lepisma. Iapyx hat nach OUDEmans 2 Krallen und ein kleines Onychium (Empodium); letzteres fehlt bei Machilis.

1) On the Campodeae, a family of Thysanura, in: Ann. Mag. nat. Hist., (ser. 3) V. 20, 1867, p. 361-378.

2 ) in: Weber, Max, Zoologische Ergebnisse einer Reise in Niederländisch-Ostindien, V. 1, p. 77, tab. 7, fig. 8. 
Ein sehr eigenthümliches Verhalten zeigen die Collembola (Fig. 4-7). Der am proximalen Ende einfach abgerundete Praetarsus ist nur wenig in das letzte Tarsalglied zurückgezogen und zeigt keine eigentliche Streckplatte. Es liegt hier offenbar ein primitiver Zustand vor, wie er auch bei Insectenlarven (z. B. bei Limnophilus, Fig. 34) angetroffen wird. Am distalen Ende zeigen sich unter einander zwei Gebilde, welche meistens als die Krallen gedeutet werden. Während kein Grund vorhanden ist, die obere nicht als echte Kralle zu betrachten, trifft diese Bezeichnung für die untere aber offenbar nicht zu. Es liegt nahe, hierin das Empodium zu erblicken; genaue Beobachtung der Lagerungsverhältnisse zeigt jedoch, dass dieses Gebilde nicht in der Medianlinie liegt, sondern etwas nach aussen. Die ventrale Medianlinie endet mit einem kleinen Höcker, welches mir als das rudimentäre Empodium zu deuten zu sein scheint. Dann wäre aber die Nebenkralle ein laterales Gebilde, vielleicht mit den Seitenläppchen homolog. Wie gewöhnlich ist der ganze Praetarsus ein einheitliches Organ, die "Nebenkralle" ist also nicht der echten Kralle gegenüber beweglich. Die Linie, welche in vielen Abbildungen von Collembolen-Füssen quer über die Wurzel der grössern Kralle verläuft, ist bloss eine Falte beim Uebergang des Basaltheils des Praetarsus in die Kralle.

Bei Podura, Anurida, Xenylla ${ }^{1}$ ) z. B. fehlt die Nebenkralle. Bei Sminthurus trägt sie einen langen Anhang.

In den Abbildungen, welche viele Forscher über diese Abtheilung ihren Arbeiten beigeben, scheinen mir die Theile des Endgliedes nicht immer genau gezeichnet zu sein, was aber für das ihnen vor Augen stehende Ziel von geringer Wichtigkeit ist. Vielfach macht es den Eindruck, als ob die sog. obere und untere Kralle beide beweglich an einem gemeinsamen Grundstück angeheftet wären, in andern Fällen scheint nur eine von beiden mehr selbständig zu sein. Obgleich ich nicht viele Collembolen untersucht habe, scheint es mir doch sehr unwahrscheinlich, dass darunter so sehr verschiedene Verhältnisse vorkommen werden, wie die Abbildungen vermuthen liessen. Relativ sehr gut sind die von Harald Schötт ${ }^{2}$ ). Wir finden hier in fig. $13,15,19$ von tab. 16 und in fig. 29 von tab. 17 auch Andeutungen des auch von mir beobachteten Höckers, welchen ich für

1) Vergl. Fousom, Japanese Collembola, in: Bull. Essex Inst., V. 29, 1897, fig. 13 .

2) North American Apterygogenea, in: Proc. California Acad. Sc., (ser. 2) V. 6, p. 169. 
das eigentliche Empodium halte. In fig. 15 von tab. 16 und fig. 29 und 32 von tab. 17 dagegen erscheint die obere Kralle wieder sehr selbständig.

Das letzte Tarsalglied umgiebt jederseits lappenartig den Praetarsus. Bei vielen Collembolen finden sich bekanntlich am letzten Tarsalglied Haare, welche an der Spitze kolbenartig erweitert sind.

Die Dermatoptera geben $\mathrm{zu}$ wenigen Bemerkungen Veranlassung. Der Praetarsus ist hier meistens weit in das letzte Tarsalglied zurückgezogen, das Empodium meistens klein, nur ausnahmsweise (z. B. bei Pygidicrana, Spongiphora) als Haftlappen entwickelt.

Auch bei den Agnatha (Fig. 8) tritt das letzte Fussglied nur wenig aus dem 5. Tarsalglied hervor; ein Empodium fehlt. In dieser Ordnung ist, wie bekannt, oft je eine der Krallen in einen Haftlappen umgewandelt. Es hat sich hierfür die Unterseite sehr in die Breite entwickelt, während auch an der Oberseite die Chitinschicht verhältnissmässig dünn geblieben ist. Haare finden sich an der Unterseite dieses „Haftlappens" nicht. Bisweilen kommt auch überhaupt an bestimmten Füssen nur eine Kralle vor [z. B. männliche Vorderfüsse von Chloeon dimidiatum STEPH.] ${ }^{1}$ ).

Auch bei den Odonata (Fig. 9) wird der Praetarsus, sowohl bei den vollkommnen Insecten wie auch bei den Larven, fast nur durch die Krallen vertreten. Ein Empodium ist nicht entwickelt. Die starke Streckplatte ist quer gerippt.

Deutlicher als selbständiges Organ entwickelt ist der Praetarsus der Plecoptera. Es endet hier die gekörnelte Streckplatte in einen unbehaarten Haftlappen. Zwischen diesem und der Streckplatte stehen 2 starke Borsten (Chloroperla grammatica PODA., Nemura variegata OL. [Fig. 10]).

Bei den Orthopteren (Fig. 11, 12) findet sich in mehreren Fällen ein als Haftlappen fungirendes Empodium, so z. B. bei den Acridiiden, den Phasmiden und den meisten Blattiden. Dieser Haftlappen pflegt unten unbehaart zu sein, während die Oberseite mit zerstreuten Härchen bedeckt ist. Bei Mantiden, Locustiden und Grylliden und unter den Blattiden bei Blabera, Monachoda, Panesthia, Heterogonia u. a. fehlt der Haftlappen. Panesthia zeigte mir auch überhaupt keine Spur vom Empodium. Bei Periplaneta findet sich zwischen Haftlappen und Streckplatte eine starke Borste.

1) Luввоск, On the development of Chloeon dimidiatum, in: Trans. Linn. Soc. London, V. 25, 1866, p. 484. 
Was die Corrodentia anlangt, so zeigte sich bei Clothilla und Psocus (Fig. 13, 14) das gleiche Verhalten. Bei beiden Gattungen ist der Praetarsus ziemlich selbständig. Das Empodium fehlt. An der Stelle, wo bei vielen Insecten die Seitenläppchen auftreten, steht hier ein borstenähnlicher Fortsatz, wie er z. B. an derselben Stelle auch bei Campodea auftritt.

Der Gelenkhöcker fällt durch bedeutende Länge auf. Am Innenrande der Krallen, nahe der Basis, steht je ein kolbiges Haar. Die Streckplatte ist zweireihig gerippt.

Auch bei Termes fehlt der Haftlappen.

Das in eigenthümlicher Weise modificirte Fussende der Thysan optera ist besonders von JORDAN ${ }^{1}$ ) eingehend untersucht worden. Dieser Forscher hat nachgewiesen, dass dasselbe besonders durch die Möglichkeit des Aus- und Einstülpens des Haftlappens von dem gewöhnlichen Verhalten abweicht. Ueberdies sind die Krallen, namentlich bei den erwachsenen Thieren, mit diesem Haftlappen fast ganz verschmolzen und nur noch als Doppelspange erkennbar. JoRDAN weist mit Recht darauf hin, dass auch schon bei Cicadellinen sich eben solches, wenngleich weniger ausgesprochen, vorfindet. Aus seinen figg. 46-58, welche hier besonders von Interesse sind, kann ich nichts herausfinden, was der Betrachtung des Blasenapparats als besonderes Glied widerspricht. Wenn JoRdAN meint, es sei unrichtig, dasselbe als 3. Tarsalglied zu deuten, so kommt dies daher, dass er die Homologie mit der Krallen tragenden Partie der übrigen Insecten erkannte und diese Partie überhaupt nicht als besondern Beinabschnitt betrachtet.

Sehr verschiedenartige Zustände treten bei den Hemiptera auf. Als Beispiele von complicirt gebildetem Praetarsus mögen Carpocoris baccarum F. (Fig. 15) und Pyrrhocoris apterus L. (Fig. 16) angeführt werden. In diesen Fällen ist der Praetarsus deutlich als besonderes Glied erkennbar. Die zweireihig gerippte Streckplatte endet in eine in der Mitte eingeschnittene Platte, welche 2 lange Borsten trägt. Es sind hier 2 unbehaarte Haftlappen vorhanden, welche in auffälliger Weise mit der Krallenwurzel articuliren. Der Gelenkhöcker des letzten Tarsalgliedes ist relativ lang.

Bei Calocoris bipunctatus L. und Cyllocoris histrionicus L. (Fig. 18), welche ich zunächst untersuchte, finden sich nun von den Haftlappen nur geringe Spuren; es ist nämlich an der Unterseite der

1) Anatomie und Physiologie der Physapoda, in: Z. wiss. Zool., V. 47,1887, p. 564. 
Krallenwurzel ein weiches Läppchen entwickelt, welches mir hier das Homologon der Haftlappen zu sein scheint. Es wären somit in dieser Ordnung die Haftlappen Anhänge der Unterseite der Krallen, also in der Ursprungsstelle verschieden von den Seitenläppchen anderer Insecten. Ich möchte daher die Hemipteren-Haftläppchen als Lobuli unguiculares unterscheiden.

Sowohl bei Cyllocoris wie bei Calocoris sind die beiden Borsten, welche sich am Ende des Empodiums vorfinden, eigenthümlich entwickelt. Es sind dieselben hier nämlich stark abgeplattet; bei Calocoris (Fig. 17) haben sie eine dreieckige, bei Cyllocoris eine unregelmässige Form.

Harpactor iracundus Scop. (Fig. 19) zeigt von den Haftlappen keine Spur. Die Krallen haben hier an der Innenseite einen starken Zahn. In Fig. 19 ist die eine Kralle nahezu losgelöst dargestellt, wodurch der hier fast eine gerade Linie bildende mediane Oberrand des Praetarsus sichtbar wird. Die Borsten am Ende des Empodiums sind hier einfach cylindrisch.

Die im Wasser lebenden Hemipteren zeigen ein kleines, wenig vortretendes Endglied. Nur die Krallen sind gut entwickelt [Mittel- und Hinterbeine von Hydrometra ${ }^{1}$ ), Naucoris (Fig. 20), Nepa]. Das Empodium ist klein und trägt am Ende 2 kleine, auffällige Borsten (Naucoris). Bekanntlich sind die Vorderbeine bei diesen Thieren oft stark modificirt. Bei Naucoris und Nepa z. B. folgt hier auf den Schenkel ein krallenähnlicher Abschnitt, der nahe am Ende noch eine Articulation aufweist. Es ist hier aber die Zahl der Beinabschnitte ebenso reducirt wie z. B. bei den Vorderfüssen der Lycaena-Männchen, und es lässt sich ohne umfassende vergleichende Untersuchungen verwandter Formen nicht sagen, mit welchen Theilen die hier vorhandenen Glieder homolog zu stellen seien. Jeden Falls enthält hier der ganze krallenähnliche Abschnitt keine Muskeln. Ob also die geläufige Annahme, dass dieses Glied der Hauptsache nach der Schiene homolog und das Endglied als einziges Tarsenglied, also ohne Krallen, aufzufassen sei, scheint mir zweifelhaft. Bei Naucoris schienen mir an der Basis der vermeintlichen Schiene auch Spuren ganz rudimentärer Glieder vorhanden zu sein. In letzterer Gattung finden sich an

1) Ich will hier bemerken, dass in der DAHL'schen Arbeit (in: Arch. Naturg., Jg. 50, V. 1, 1884) in der Tafelerklärung eine Verwechslung zwischen den Figuren von Hydrometra und Scatella stattgefunden hat. 
Schienen und Tarsus starke Dornen, welche dieselbe Farbe wie die Krallen haben und diesen auch sonst sehr ähnlich sehen, weshalb TuFfenWEST sie als Vorläufer derselben ansieht. Doch sind sie nur als besonders entwickelte Haare aufzufassen, was aus der Weise hervorgeht, in welcher sie in der Haut eingepflanzt sind.

Belostoma hat an den Vorderfüssen nur eine einzige Kralle. Die letzten Tarsenglieder sind an diesen Füssen bedeutend verkürzt.

Eigenthümlich ist das Endglied bei der mir nicht zugänglichen Gattung Halobates. Wie aus den bezüglichen Angaben in der Literatur erhellt, sollen hier die Krallen an den Vorderbeinen in der Mitte des letzten Tarsalgliedes eingepflanzt sein, während sie bei den Mittelund Hinterbeinen der Spitze näher gerückt sind. Nach den figg. 1, 5 und 13 auf tab. 3 der Abhandlung von Buchanan White ${ }^{1}$ ) wird dieses Verhalten wohl bloss durch die Dorsalverlängerung des letzten (d. h. hier des 2.) Tarsalgliedes verursacht. Auf ein Empodium bezieht sich wohl der in derselben Abhandlung ${ }^{2}$ ) befindliche Satz: „From between and a little behind the claws arises a thin ribbonlike process about as long, but only half as broad, as the claws, curved backwards, equally wide and thin throughout, and truncate at the apex. The use of this process is unknown."

Unter den $\mathrm{H}$ e m i p ter a Ho moptera ist zunächst bei den Cicaden das Endglied dadurch vereinfacht, dass vom Haftlappen jede Spur fehlt. Die Streckplatte ist hier körnig. Bemerkenswerth ist die Thatsache, dass auf der Oberseite des Praetarsus, zwischen den Krallen, einige starke Borsten vorhanden sind.

Dagegen sind bei Aphrophora und Tettigonia (Fig. 21-23) die Haftlappen wieder sehr bedeutend entwickelt; in letzterer Gattung hat fast die ganze Unterseite der Kralle an der Bildung der Haftläppchen Antheil.

Die Krallen tragen bei Aphrophora einige starke Borsten.

Die einzige Kralle von Pediculus (Fig. 24) ist sehr gross; oberseits articulirt sie mit einem stark entwickelten Gelenkhöcker des Tarsengliedes. Streckplatte und Gleitfläche sind normal gebildet. Die Unterseite des Tarsengliedes endet mit einem weichen, farblosen, lappenförmigen Anhang.

Besonders deutlich war hier in der Kralle eine Trachee sichtbar.

1) On the pelagic Hemiptera coll. by the Challenger Expedit., in: Results Challenger Exped., V. 7, 1883.

2) l. c. p. 46 . 
Den zwei- bis viergliedrigen Füssen der männlichen Strepsipteren fehlt jede Spur von Krallen (KoLbe). Nach einer Figur Westwood's folgt jedoch auf das letzte Tarsalglied eine Art Haftlappen, welcher hier wohl den Praetarsus vertritt.

Bei den Neuropteren finden sich wieder verschiedenartige Verhältnisse. So hat Sialis lutaria L. (Fig. 25) wieder einen fast auf die Krallen reducirten Praetarsus, indem das Empodium hier sehr klein bleibt. Letzteres trägt am Ende ein kurzes Haar. In dieser Gattung ist das 4. Tarsalglied scheibenförmig und hat wohl die Function des Haftlappens übernommen. Auch bei Rhaphidia und Corydalis ist das Empodium sehr unbedeutend entwickelt.

Das Empodium der Hemerobiidae dagegen ist sehr breit; die Unterseite ist nur am distalen Ende mit feinen, kurzen Härchen besetzt. Hinter der gekörnelten Streckplatte war das Empodium von 2 schief nach aussen gerichteten Chitinstreifen gestützt, welche je 3-4 Borsten tragen.

Das 5. Tarsalglied ist an der Unterseite stark verkürzt. Druckborsten fehlen. Der Gelenkhöcker ist auffallend breit und dunkel gefärbt (Chrysopa, Fig. 26, 27; Hemerobius, Fig. 28).

Auch bei Mantispa pusilla (Fig. 29) ist der Haftlappen (das Empodium) sehr breit; die ganze Unterseite ist hier mit zahlreichen kurzen Härchen besetzt, welche aber am Ende spitz sind, also keine eigentlichen Hafthaare darstellen. Die nach oben umgeschlagenen Seiten des Pulvillus zeigen schuppenartige Zeichnung.

Bei Nemoptera fehlt das Empodium.

Dasselbe ist auch bei den Myrmeleontidae (Fig. 30) wenig entwickelt. Nur am Ende sind einige Borsten vorhanden. Denselben Zustand bietet Ascalaphus dar (Fig. 31).

Das Empodium von Panorpa communis L. (Fig. 32) zeigt Aehnlichkeit mit dem von Mantispa, wie aus Vergleichung der Figg. 29 und 32 erhellt. Der breite Haftlappen ist hier aber unterseits nur an der Wurzel behaart. Die Oberseite trägt zahlreiche kurze Haare. Sehr entwickelt ist hier die Strecke, welche zwischen Haftlappen und der Streckplatte liegt (die Strecksohle OckLen's), sie wird von 2 quer verlaufenden parallelen Chitinstäben gestützt. Von den Seitenläppchen findet sich hier nur eine Spur.

Bei den Trichopteren (Fig. 33) endet das Empodium mit einem unbehaarten Haftlappen, der von einem Chitinring gestützt wird. Es finden sich hier zuerst gut entwickelte, jederseits behaarte Seitenläppchen von länglich dreieckiger Form. Bisweilen kommt 
in der Mitte der Strecksohle eine kurze, aber starke Borste vor (Limnophilus). Die Streckplatte ist schuppig befeldert, die Strecksohle und die Seitenlappen sind gleichmässig fein behaart. Am obern Ende des letzten Tarsalgliedes steht eine lange Borste, welche also zwischen den Krallen hervorragt. Im Ganzen ist die Uebereinstimmung mit den Lepidopteren sehr gross.

Bei den Trichopterenlarven (Fig. 34, 35) enden die Beine mit einer einzigen Kralle. Eine eigentliche Streckplatte ist hier noch nicht entwickelt; das proximale Ende des Praetarsus erinnert an das Verhalten bei den Collembolen. Die Kralle kann an der Unterseite eine Borste tragen, z. B. bei Enoicyla pusilla Burm. Hier ist die Kralle der Vorderbeine so lang wie das einzige Tarsalglied. An letzterm, wie auch an der Schiene und am Thorax selbst, kommen sehr lange, schwarze Tasthaare vor.

Die Lepidopteren zeigen fast dasselbe Verhalten wie die Trichopteren. Dass sich hier gewöhnlich ein grosser medianer Haftlappen findet, welcher von einem Chitinring gestützt wird, ist schon von DaHL und Ockler mitgetheilt. Die Unterseite dieses Haftlappens ist nackt. Relativ wenig entwickelt ist derselbe bei Vanessa, während er in den Gattungen Papilio, Colias, Parnassius u. s. w. ganz fehlt.

Die Seitenläppchen sind meistens gut entwickelt; breit und am Rande tief eingeschnitten zeigten sie sich bei Luperina (Fig. 39-41), Cidaria, Eurrhypara (Fig. 37), Micropteryx, Aciptilia; zwei- oder dreispaltig bei Arctia caja (OCKLER), nach Doyère ${ }^{1}$ ) zweispaltig bei Heliconius callicopis Cram. und Cethosia (Colaenis) julia F., schmal und sehr lang bei Vanessa und Pyrameis (Fig. 42). Dagegen fehlen sie bei Papilio, Parnassius u. a.

Die Dorsalseite des Praetarsus trägt zwischen der Krallenwurzel bei mehreren Lepidopteren eine lange Borste (Micropteryx calthella L., Aciptilia xanthodactyla TR. [Fig. 38], Eurrhypara urticata L. [Fig. 37], Cidaria fluctuata L., Luperina monoglypha HFN., Pieris rapae L.). Bei letzterer Art ist dieselbe aber relativ kurz und erreicht nicht die halbe Länge der Krallen.

Bei oberflächlicher Betrachtung scheint auch bei Raupen bisweilen eine Art Pulvillus vorhanden zu sein. In Sundevall's Abhandlung über die Extremitäten der Insecten ${ }^{2}$ ) findet man dies schon angegeben,

1) Observations sur quelques genres d'Hémiptères et de Lépidoptères, in: Ann. Soc. ent. France, 1837, p. 261.

2) Om Insekternas Extremiteter u. s. w., in: Svensk. Vet. Akad. Handl., V. 3, 1860, p. 6. 
indem er sagt, die Raupen haben einen „klo, som ar enkel, man ofta undertill forsed med et litet bihang, ungefahr sasom pulvilli hos de utbildade Insekterne". Die genauere Untersuchung zeigte mir jedoch, dass es sich in diesen Fällen bloss um Anhänge des Tarsalgliedes handelte. Dieses trägt nämlich mehrere Borsten, von welchen oft einige ausserordentlich in die Breite entwickelt sind. Bei Harpyia vinula L. fand ich 1, bei Euchelia jacobaeae L. (Fig. 43) 3, bei Abraxas grossulariata L. 2 solche Borsten. Der Praetarsus selbst erscheint immer bloss als einfache Kralle, ohne besonders ausgezeichnete Streckplatte.

Bei den Coleopteren ist der Praetarsus meistens stark in das Tarsenglied zurückgezogen. Wohl am meisten möchte dies bei Curculioniden der Fall sein, wo es an der Wurzel oft sowohl ober- als unterseits von Fortsätzen dieses Gliedes umklammert wird (man vergl. Fig. 44 von Protocerius colossus OLIV.). Ausserdem sind hier die Krallen an der Wurzel ,verwachsen“. Das Empodium zeigt gewöhnlich keine bedeutende Entwicklung und hat meistens gar keine Bedeutung als Haftorgan. Am Ende kamen oft einige Borsten vor (Hydrophilus piceus L.). Nach OCKLER soll es bloss bei den sehr kleinen Trichopterygiden als Haftorgan fungiren. Bei Trichopteryx fand ich aber, dass es haarförmig ist und am Ende spitz; dagegen ist es bei Ptenidium evanescens MARSH (Fig. 45) am Ende kolbenartig erweitert.

Bekanntlich sind bei mehreren Lamellicorniern die Krallen ungleich gross (Fig. 46); bisweilen ist nur eine Kralle übrig, so z. B. an den Hinterbeinen von Hoplia. Die einzige Kralle besitzt hier jedoch 2 Gelenkhöcker. Auch die Pselaphiden haben nur eine Kralle.

Bei einigen Mordelliden und den meisten Melyriden kommt unter den Krallen je ein häutiges Läppchen vor (Dasytes plumbeus MüLL., Fig. 47). Besonders stark entwickelt ist dasselbe bei Psilothrix nobilis GYLL. (Fig. 48). Es sind hier überdies die Krallen ungleichartig entwickelt; die eine Kralle ist normal und hat an ihrer Unterseite das häutige Läppchen, während die andere ganz in die Bildung dieses Läppchens mit hineingezogen wurde und selbst mit dünner Chitinschicht bekleidet ist. Nur an der Wurzel der Oberseite ist dieselbe bedeutender entwickelt und schwarz. Dieser Haftlappen ist unten ganz nackt, oberseits mit wenigen kurzen, steifen Härchen besetzt. Es hat hier somit eine eben solche Umbildung der Kralle stattgefunden, wie sie auch einem Theil der Ephemeriden-Krallen eigenthümlich ist. Ueber die sogenannten ,gespaltenen Krallen“ von Meloë hat 
OCKLER schon richtig bemerkt, dass hier die Nebenkrallen, wenngleich in ihrer Form und Beschaffenheit den eigentlichen Krallen ähnlich, doch wegen ihrer Stellung eher den Seitenläppchen der Lepidopteren $\mathrm{zu}$ vergleichen sind. Ich möchte noch hinzufügen, dass sie nicht, wie OCKLER $^{1}$ ) anführt, am Grunde mit den eigentlichen Krallen verbunden sind, sondern sich, wie aus Fig. 49 und 50 erhellt, selbständig aus dem häutigen Seitentheil des Praetarsus erheben, was ihre Homologie mit echten Seitenläppchen noch wahrscheinlicher macht. Fig. 50, welche sich auf Iletica bezieht, zeigt überdies, dass bei dieser mit Meloë verwandten Gattung die Nebenkrallen gar nicht krallenartig sind, sondern weiche, am Ende stumpfe Läppchen darstellen, also schon sehr den Seitenläppchen von gewissen Lepidopteren ähnlich sind. Das Empodium ist hier nur als unscheinbarer Höcker vorhanden.

Ich will noch darauf hinweisen, dass bei Curculioniden das Endglied oft durch die Anwesenheit eigenthümlicher Borsten complicirt wird. So zeigt Fig. 51 am Praetarsus von Sitona lineatus L. 2 breite, platte Borsten, welche je in der Aussenseite einer Kralle eingepflanzt sind. Das Empodium ist bei dieser Art am Ende zweihörnig; jedes Horn hat einen langen, haarförmigen Fortsatz.

Bekanntlich fehlt bei Anoplus plantaris NAEz. (Fig. 53) der Praetarsus ganz; das scheibenförmige letzte Tarsalglied ist an der Unterseite mit vielen Hafthaaren besetzt.

Was die Larven der Coleopteren betrifft, so haben diese gewöhnlich nur je eine Kralle an den Beinen, so z. B. die Larve von Melolontha. Eine besondere Streckplatte ist hier nicht entwickelt.

2 Krallen kommen bei Carabiden- und Dytiscidenlarven vor; bei Dytiscus (Fig. 52) fand ich die Streckplatte klein, aber doch deutlich erkennbar; das kleine Empodium endet mit 2 Borsten, welche bei Dytiscus selbst kurz sind; länger fand ich sie bei einer andern Dytiscidenlarve, von welcher ich nicht weiss, zu welcher Gattung sie gehört.

Es ist hier der Ort, die eigenthümlichen Verhältnisse der Meloidenlarven $\mathrm{zu}$ erwähnen. Es wurde früher behauptet, dass bei den jüngsten Larven 3 Krallen vorhanden seien, weshalb diesen Thierchen auch der Name Triungulinus beigelegt wurde. Der Zeit war man über ihre weitere Entwicklung noch ganz im Unklaren. Die Untersuchungen

1) Das Krallenglied am Insectenfuss, in: Arch. Naturg., Jg. 56, V. 1,1890 , p. 260. 
von Riley und Brauer haben aber gelehrt, dass es sich hier immer um eine eigenthümlich modificirte Kralle handelt. BRAUER ${ }^{1}$ ) unterscheidet nach dem Verhalten dieser Kralle zwei Gruppen. In der ersten besitzen die Larven scheinbar 3 ungleich lange Klauen, d. h. eine grosse Klaue, an welcher am Grunde hinter einander je eine klauenförmige Borste entspringt (es gehören hierzu die Larven von Sitaris, Mylabris, Epicauta, Lytta).

In der zweiten Gruppe, welche nur Meloe selbst umfasst, haben die Larven eine lange, am Ende lanzettförmig erweiterte, etwas abwärts gebogene mittlere Klaue und 2 gleich lange (eine jederseits), hakenförmige, kürzere Seitenklauen, die etwas aus- und abwärts gebogen sind und mit der mittlern einen Dreizack bilden. Die Seitenklauen bilden durch ihren verwachsenen Grund den Ansatz der Mittelklaue. Auf p. 139 fügt Brauer noch zum Ueberfluss hinzu, dass nach dieser Deutung die Meloidenlarven also im Grunde nur eine Klaue haben und dass die 3 scheinbar selbständigen Klauen im gleichen Sinne und gleichzeitig an einem Beine bewegt werden.

Complicirter als bei den Coleopteren ist der Praetarsus der Hymenopteren gebildet. Gewöhnlich tritt er hier besonders deutlich als selbständiges Glied auf; zwischen den Krallen findet sich der Regel nach ein grosser, unten nackter Haftlappen. Besonders eigenthümlich ist in dieser Ordnung die grosse Entwicklung der Oberseite des Praetarsus. Es findet sich hier fast immer zwischen der Krallenwurzel eine mit dicker Chitinschicht versehene Region, welche mehrere und oft starke Borsten trägt. Es ist dies die Stützplatte OckLER's (= „Druckplatte“ DAHL's). Bei Formica trägt dieselbe 2 starke Borsten, bei Bembex (Fig. 54) und Vespa (Fig. 58) 2 eben solche und überdies viele kleinere. Gross und mit vorspringenden Spitzen versehen ist diese Platte bei Bombus. Besonders entwickelt ist diese Region aber bei den Pompilidae (Fig. 55-57). An der Oberseite zeigt dieselbe hier einen Anhang in der Form einer ovalen Scheibe, deren Inneres durch ein ovales Loch mit dem Innern des Praetarsus selbst in offener Communication steht. Diese Platte, welche von OCKLER Schutzplatte genannt wurde, besitzt am distalen Rande eine Reihe starker Borsten. Wenn Ockler sagt: „Bei diesen (d. h. den Pompiliden) ist die obere Stützplatte der Haftläppchen nicht direct am Krallenhöcker eingelenkt, sondern mit der Unterseite einer abge-

1) Ueber die Verwandlung der Meloiden, in: Verh. zool.-bot. Ges. Wien, V. 37, 1887, p. 640. 
rundeten, flachschaligen Platte fest verwachsen, die ihrerseits am Krallenhöcker beweglich befestigt ist", so kann ich seiner Auffassung in so fern nicht beistimmen, als mir diese "Schutzplatte“ bloss eine nach vorn vorspringende Falte auf der Mitte der Dorsalplatte des Praetarsus zu sein scheint, wie es der Längsschnitt (Fig. 57) sogleich zeigt. Der mit dem Krallenhöcker articulirende Theil ist also auch hier der Hinterrand dieser Dorsalplatte.

Der Haftlappen von Bombus (Fig. 59) ist verhältnissmässig klein, sonst normal gebildet ${ }^{1}$ ).

Bei vielen Hymenopteren tragen die Krallen starke Borsten (z. B. bei Formica, Vespa, Bombus).

Sehr einfach ist das Verhalten der Puliciden (Fig. 60). Es ist hier weder vom Empodium noch von Seitenläppchen eine Spur vorhanden. 2 dicke, kurze Borsten stehen am untern Ende des letzten Tarsalgliedes.

Die Dipteren habe ich eingehender als die übrigen Ordnungen untersucht. Es wurde dies zunächst dadurch veranlasst, dass ich mich seit mehreren Jahren mit der Untersuchung der niederländischen Dipteren beschäftige und mir also reiches Material $\mathrm{zu}$ Gebote stand, dann auch, weil viele Dipterenfamilien nur kleinere Thiere enthalten, welche mit Hinsicht auf unser Tema nur erst sehr unvollständig bekannt sind, obgleich gerade die Beschaffenheit des Fussendes als Familiencharakter bisweilen, so z. B. in den Auseinandersetzungen Osten-Sacken's, eine Rolle spielt. Doch zeigt auch dieses Fussende hier eine so verschiedenartige Bildung, dass die genauere Untersuchung nicht überflüssig erscheint. Im Allgemeinen lässt sich sagen, dass das letzte Fussglied der Dipteren in der Regel sehr deutlich als selbständiges Organ auftritt. Die Streckplatte, die Gleitsohle und das Eınpodium lassen sich meistens ohne Mühe erkeunen; in der Regel sind 2 Seitenläppchen (Lobuli laterales) vorhanden, welche hier zweifelsohne als Haftapparate fungiren. - Die Besprechung der verschiedenen Familien will ich mit den Tipulidae anfangen, weil diese durch das an der Unterseite unbehaarte Empodium von allen andern

1) In den sich auf Apis mellifica beziehenden, sonst verdienstvollen Abbildungen von Cheshire (Bees and bee-keeping, London 1886) ist in der von PACKARD in sein Textbook übernommenen Figur (fig. 105, p. 98) die Strecksohle unrichtig gezeichnet. Dieselbe ist überhaupt breiter und grösser und über die ganze Fläche mit Härchen besetzt, also nicht bloss am distalen Rande. 
verschieden sind. Für Tipula wurde dies schon von Tuffen West ${ }^{1}$ ) und DAHL ${ }^{2}$ ) mitgetheilt; ich fand dieses Verhalten aber bei den verschiedensten Gattungen dieser Familie wieder, so bei Ctenophora flaveolata F. (Fig. 61-63), Cylindrotoma distinctissima MeIG. (Fig. 64), Eutonia barbipes MeIG., Limnophila ferruginea MeIg., Pedicia rivosa L. (Fig. 65-67), Amalopis tipulina EGG. (Fig. 69), Trichocera regelationis L. (Fig. 68) und hiemalis DE G., Symplecta stictica MeIG., Erioptera cinerascens MEIG.

Bei allen diesen ist das Empodium am distalen Ende erweitert, oben in der Mitte meistens kielförmig erhoben; dieser Kiel wird distalwärts allmählich höher. Die Oberseite ist meistens kurz behaart; bei Cylindrotoma finden sich am Rande längere Haare. Trichocera hat eine fast nackte Oberseite, es zeigen sich hier nur an der Wurzel 2 steife Härchen. Relativ klein ist das Empodium bei Symplecta, während es in der Unterabtheilung der Limnobiina (Fig. 70) völlig fehlt, wie schon von Osten-SAcken ${ }^{3}$ ) u. A. bemerkt wurde. Nach letzterm ist auch bei einigen zu seiner Abtheilung Limnobiina anomala gehörigen Gattungen (nämlich bei Rhamphidia, Toxorrhina, Elephantomyia, Antocha, Elliptera und Thaumastoptera) das Empodium rudimentär. Die Strecksohle zeigt eine körnige Oberfläche (Ctenophora, Limnobia).

Die lateralen Anhänge sind sehr wenig entwickelt; oft wird ihre Stelle nur durch längere Behaarung angedeutet.

Bei Limnophila sind neben der Basis der Klauen nur einige wenige lange Haare vorhanden.

Das 5. Tarsalglied ist meistens an der Ventralseite bedeutend verkürzt (C'tenophora, Limnobia, Eutonia, Amalopis). Bisweilen, z. B. bei Ctenophora, Pedicia, ist es auch an der Dorsalseite etwas ausgeschnitten. Besonders ist dies bei Cylindrotoma der Fall, wodurch hier die Wurzel der Klauen durch 2 laterale, lappenförmige Fortsätze des 5. Tarsalgliedes umgeben erscheint. Bei Erioptera, Trichocera u. a. ist dieses Glied an der Unterseite nur unbedeutend verkürzt. Typische, am Ende erweiterte Hafthaare fehlen den Tipuliden wohl ganz.

Besonders wichtig ist das Verhalten der Ptychopteridae (Fig. 71-73). Es findet sich hier zunächst, wie bei den Tipuliden, zwischen den p. 418.

1) The foot of the fly, in: Trans. Linn. Soc. London, V. 23, 1861,

2) in: Arch. Naturg., Jg. 50, V. 1, 1884, p. 178.

3) Monographs of the Diptera of North America, in: Smithsonian misc. Coll., V. 8, p. 23. 
Krallen das Empodium. Dasselbe ist hier oben bedeutend weniger entwickelt und als Haftorgan ohne Bedeutung, indem unter demselben eine grosse Scheibe vorhanden ist, welche unterseits mit Hafthaaren besetzt ist. Diese Haftscheibe entspringt am Ende der Strecksohle und lässt sich als Fortsatz derselben auffassen. Ich nenne sie Sohlenläppchen (Lobulus plantaris).

Indem dieser Sohlenlappen den meisten höhern Dipteren eigenthümlich ist, daselbst aber das Empodium entweder ganz fehlt oder doch nur als kleines Rudiment vorkommt, bildet Ptychoptera ein wichtiges Bindeglied zwischen Tipuliden und den übrigen Dipteren, wie es auch in andern Hinsichten der Fall ist.

Es möge noch hinzugefügt werden, dass das Empodium oberseits von einer welligen, fein behaarten Haut bedeckt ist, während die Unterseite flach und bräunlich gefärbt erscheint. Die Oberseite des Sohlenläppchens trägt nur am distalen Ende kurze Härchen, welche, wie bei allen Dipteren an dieser Stelle, einfach zugespitzt sind. Die Seitenläppchen sind klein, lang behaart. Die Streckplatte ist beschuppt. Der ganze Praetarsus überhaupt ist klein. Das 5. Tarsalglied ist an der Unterseite nur wenig ausgeschnitten. Besondere Druckborsten sind nicht vorhanden.

Die untersuchten Mycetophilidae (Fig. 74-76) zeigten ein rundes Sohlenläppchen, welches unten mit Hafthaaren besetzt ist, an der Oberseite aber nackt sein kann (z. B. Glaphyroptera). Die Seitenläppchen sind klein; bei Sciara (Fig. 76), wo das Empodium selbst ziemlich klein ist, fand ich sie grösser. Nach RüBSAameN ${ }^{1}$ ) sind auch bei den exotischen Gattungen Rhynchosciara und Hybosciara die seitlichen Haftläppchen gut entwickelt. Das letzte Tarsalglied ist an der Unterseite nur ganz wenig ausgeschnitten (Mycetophila, Sciara, Glaphyroptera). Die Strecksohle ist zweireihig gerippt.

Bei den meisten Cecidomyidae (Fig. 77) ist nur das Sohlenläppchen vorhanden, dieses aber ziemlich gross und unten mit Hafthaaren, oben mit kurzen, spitzen Härchen besetzt. Doch sind auch in mehreren Fällen die Seitenläppchen mehr oder weniger entwickelt. So finden sich z. B. nach KIEFFER ${ }^{2}$ ) 3 Haftläppchen unter den Lasiopterinae bei Lasioptera Meig., Stephaniella Kieff., Arnoldia Kieff., Dasyneura Rond., Dryomyia KIEFF.; unter den Asphondylinae bei den

1) Die aussereuropäischen Trauermücken des Museums f. Naturk. zu Berlin, in: Berlin. entom. Zeitschr., V. 39, 1894, p. 19 und tab. 3, fig. 24.

2) Synopse des Cecidomyies d'Europe et d'Algérie décrites jusqu'à ce jour, in: Bull. Soc. Hist. nat. Metz, 20. cahier (sér. 2, V. 8), 1898. 
Gattungen Rhopalomyia RüBs., Oligotrophus KiefF., Janetiella KIEFF., Mayetiola KiefF., Mikiola Kieff., Hormomyia H. Löw; unter den Diplosinae bei Putoniella KIEFF. und unter den Epidosinae bei Colomyia KiefF. und Clinorhytis KiefF. Dagegen fehlt auch das Sohlenläppchen selbst bei Wasmanniella KIEFF,, während es bei Aprionus und einigen verwandten Gattungen unter den Campylomyzinen rudimentär ist.

Was die Chironomidae anlangt, so ist es schon lange bekannt, dass in der Gattung Ceratopogon das Ende des Fusses sehr verschiedenartig beschaffen sein kann. Schon W INNERTz $^{1}$ ) bat darauf hingewiesen, dass bei einigen Arten die Klauenglieder mit haarigen Pulvillen versehen sind und dass bei andern die Klauen Borstenhaare statt Pulvillen tragen, während eine dritte Abtheilung weder Pulvillen noch Borstenhaare besitzt. Als Beispiel der erstern Gruppe untersuchte ich zunächst C. niger Wins. und pavidus Wins. (Fig. 81). Das von Winnertz als Pulvillus gedeutete Sohlenläppchen ist hier eine eiförmige Scheibe, welche an der Oberseite nackt ist, unten aber trägt dieselbe zahlreiche längere Haare. Dasselbe Verhalten zeigte sich bei $C$. rostratus Wins. (Fig. 78, 79); hier findet sich aber überdies an der Aussenseite der Krallenwurzel ein längeres, unten gebogenes Haar.

C. pulicaris L. (Fig. 80) gehört in die Gruppe von Winnertz, welche "Borstenhaare statt Pulvillen" besitzen soll. Es zeigte sich hier das Sohlenläppchen wohl vorhanden; es ist aber sehr schmal, nach oben gebogen; die Unterseite ist mit langen Borstenhaaren besetzt. Einen solchen Sohlenfortsatz werden wir bei sehr vielen höheru Dipteren wiederfinden.

Als Beispiel derjenigen Gruppe, wo der Pulvillus ganz fehlt, habe ich C. venustus MeIG. (Fig. 82) und nitidus MACQ. untersucht. Vom Praetarsus sind hier besonders die Krallen, auf Kosten der übrigen Theile, ausgebildet. In dieser Gruppe kommen häufig Anhänge an den Krallen vor, entweder in der Form eines Zahns an der innern Seite (z. B. bei C. bicolor MeIG., C. solstitialis Winn.) oder eines nach aussen stehenden Anhangs an der Wurzel der Kralle (z. B. bei C. venustus Meig., C. nitidus MacQ.), welcher von Winnertz als "Nebenklaue" bezeichnet wird. Beide sind aber blosse Fortsätze der Kralle selbst, ohne weitern morphologischen Werth; sie lassen sich (wenigstens die äussern Anhänge) vergleichen mit dem Haar, welches

1) Beitrag zur Kenntniss der Gattung Ceratopogon, in: Linn. entomol., V. 6, p. 1. 
sich bei $C$. rostrata und auch bei $C$. pulicaris an der Krallenwurzel befindet.

Das 5. Tarsalglied ist bei Ceratopogon unten nur wenig verkürzt. Obwohl für unser Thema von weniger Interesse, will ich hier noch die an der Spitze zwei- bis dreispaltigen dicken Börstchen erwähnen, welche sich in dieser Gattung häufig an den Füssen vorfinden. Eben solche besitzen auch die Platypezinen. Comstock hat sie schon von Platypeza abgebildet, und ich selbst fand sie auch bei Callomyia amoena wieder.

Besonders interessirte mich das Verhalten der Gattung Chironomus. Es wurde nämlich von Osten-SaCken behauptet, dass hier ein gespaltenes Empodium vorhanden sei, während, so wie in seiner ganzen Hauptabtheilung der Nemocera vera, die gewöhnlich Pulvillen genannten Seitenläppchen fehlen sollten. Es liess die nahe Verwandtschaft mit Ceratopogon auch nicht vermuthen, dass hier ein ganz anderes Verhalten vorliegen sollte. Doch zeigte sich sehr bald, dass dies der Fall ist. Bei mehreren Arten (Ch. plumosus L., barbipes Staeg. [Fig. 83, 84], rufipes L. [Fig. 85], nubeculosus Meig.) habe ich mich überzeugen können, dass das zweilappige Organ OstenSACKEN's wirklich die Pulvillen sind, während das Sohlenläppchen als sehr gut erkennbares, selbständiges Gebilde auftritt. Die Seitenläppchen sind eiförmig und unten mit zarten Hafthaaren besetzt. Das Sohlenläppchen ist, wie bei Ceratopogon pulicaris L., aufgebogen, unten zweireihig beborstet, oben unbehaart. Bei Ch. rufipes L. ist es kürzer und breiter als bei den übrigen untersuchten Arten. Die Streckplatte ist oval, zweireihig gerippt. Das 5. Tarsalglied ist unten nicht stark ausgeschnitten. Besondere Druckborsten fehlen.

In den mit Chironomus verwandten Gattungen Orthocladius, Cricotopus und Metriocnemus, von denen resp. die Arten O.dilatatus v. D. W., Cr. sylvestris F. und $M$. albolineatus MeIG. (Fig. 86) untersucht wurden, ist das Sohlenläppchen so wie bei Chironomus gebildet; besonders lang ist es bei Cricotopus. Dagegen fehlen hier die Seitenläppchen entweder ganz oder sind nur durch dichter und länger behaarte Stellen am Praetarsus angedeutet. Letzteres Verhalten zeigte sich auch bei Tanypus nervosus MeIG. (Fig. 87). Das Sohlenläppchen ist hier höher als bei Chironomus, sonst ebenso beschaffen.

Es zeigte sich also, dass ein kammförmiges Sohlenläppchen, wie es DEBY zuerst bei einem aberranten, dem Meeresstrand angehörigen Chironomiden (Psamathiomyia pectinata DEBY) angab ${ }^{1}$ ), in dieser

1) in: Journ. microsc. Soc. London, 1889, p. 80, tab. 4, fig. 9. 
Familie gar keine Ausnahme bildet. Bei der genannten Art ist das Sohlenläppchen nur relativ stark entwickelt, während dis Seitenläppchen fehlen. Im Uebrigen scheint mir die Deby'sche Figur vom Ende des Fusses dieser Fliege wohl nicht ganz richtig, weil die Krallen ganz vom Sohlenläppchen gesondert am letzten Fussglied entspringen sollen, was mit dem Befund bei andern Dipteren gar nicht stimmt.

Was die Culicidae (Fig. 88-93) anlangt, so finden wir in der Monographie Ficalbi's über die europäischen Vertreter dieser Familie schon einige wichtige Angaben. Namentlich hat dieser Autor die Pulvillen (Seitenläppchen) und das Sohlenläppchen mit der Streckplatte hier richtig beschrieben und abgebildet. Doch wurde ihm der $\mathrm{Zu}$ sammenhang dieser Gebilde unter einander und mit dem 5. Tarsalglied nicht ganz deutlich, indem er die Streckplatte als von den Pulvillen gesonderten, selbständigen Anhang darstellt, während die Pulvillen Anhänge der Krallen sein sollen ${ }^{1}$ ). Er sagt (p. 179 seiner Abhandlung) nämlich Folgendes: L'apparecchio scansorio risulta di tre parti ben distinte, quasi direi di ben distinti tre organi: due pari e correspondentesi bilateralmente, uno impari. . . . G Gli organi pari sono rappresentati da due cuscinetti, che si trovano alla base di attacco di ciascheduna unghia od artiglio, e la base stessa comprendono. . . . L'organo impari si attacca in una intaccatura ventrale dell' estremo dell' ultimo articolo tarsale: consta di un corpo chitinico, basale, dal quale si eleva un prolungamento, che si partisce in numerose setole: questo prolungamento è situato nel mezzo ai due cuscinetti o pulvilli poco sopra accennati e alle due unghie, ed evidentamente rappresenta un empodio plumiforme, ma non pulvilliforme." Wie aus meinen Figg. 88-91 ersichtlich, sind aber auch hier Pulvillen und Empodium Anhänge eines selbständigen Gliedes, wozu auch die Krallen gehören. Ein solches, kamnartig beborstetes, schmales Sohlenläppchen fand ich bei Culex pipiens L. und auch bei Anopheles maculipennis Meig. Bei Culex annulatus Schrank ist das Sohlenläppchen viel weniger entwickelt ; es ist hier nicht nach oben umgebogen, kürzer und dicker, auch dunkler; bei dem $q$ erreicht es hier nur die halbe Länge der Krallen, während es bei Cul. pipiens L. fast so lang wie die Kralle ist.

Die Pulvillen (Seitenläppchen) bleiben meistens klein; bei $A n$ opheles maculipennis MeIg. und Culex annulatus Schrank $q$ sind sie fast nur durch die längere Behaarung erkennbar; besser entwickelt

1) Revisione sistematica delle specie europee della famiglia delle Culicidae, in: Bull. Soc. entom. Ital., V. 28, 1896, p. 108. 
zeigten sie sich bei Corethra plumicornis F. (Fig. 92). Bei dieser Art wurden sie schon von MeINerT ${ }^{1}$ ) beobachtet. In seiner Figur ist aber das Sohlenläppchen unvollständig angegeben. Lang, sehr schmal und lang beborstet ist der Pulvillus der Vorder- und Mittelfüsse bei dem Männchen von Culex pipiens L. (Fig. 88). An diesen Füssen sind die Klauen ungleich gross, und nur neben der grossen Kralle findet sich hier ein solches Seitenläppchen. Dieselbe sexuelle Verschiedenheit in den Krallen ist von mehreren Culiciden bekannt; es hat sogar Lynch ARRiBalzaga ${ }^{2}$ ) mehrere Gattungen auf die Beschaffenheit der Krallen gegründet. So sind z. B. in seiner Gattung Culex die Krallen der ठठ ungleichartig, bei den of gleich gross, in beiden Fällen aber einfach, d. h. ohne Zahn. Bei Heteronychus haben sie an den Vorder- und Mittelfüssen der $ठ \delta$ einen Zahn und sind von verschiedener Grösse; bei den 우 sind sie gleich gross, aber auch mit einem Zahn. Die Psorophora- $\uparrow+$ haben tief gespaltene Krallen, während sie bei den $\delta \delta$ unten einen langen Zahn tragen. Ochlerothatus hat in beiden Fällen in der Mitte der Krallen einen Zahn u. s. w.

Bei Culex pipiens L. fand ich bei den Weibchen alle Krallen ziemlich klein und einfach. So sind auch die Hinterfüsse des đo gebildet; an den Vorder- und Mittelfüssen aber ist die vordere Kralle bedeutend grösser als die hintere, während sich bei ersterer an der Unterseite ein grosser Zahn vorfindet, bei letzterer aber ein kleiner Zahn, an der Aussenseite, nahe an der Wurzel.

Auch das 5. Tarsalglied hat bei dem $\delta$ eine andere Form als bei dem ․

So wie in andern Hinsichten, zeigen die Dixidae (Fig. 93) auch in dem Bau des Praetarsus eine Annäherung an die Culiciden. Dieses Glied ist hier deutlich als selbständige Bildung erkennbar. Das Sohlenläppchen ist wie bei Culex pipiens L., und die Krallen zeigen hier ähnliche Fortsätze an der Wurzel, wie sie sich oft bei Culiciden finden. Beide Krallen des Mittelbeins (Dixa nigra Meig., aestivalis + MeIG.) haben nahe an der Wurzel an der Aussenseite einen langen, haarähnlichen Fortsatz. Bei der einen Kralle folgen darauf noch 3 viel kürzere Härchen.

Ein breites, scheibenförmiges Sohlenläppchen ist den Psychodidae (Fig. 94-86) eigen. Es ist hier wieder oben nackt, unten mit deutlich geknöpften Hafthaaren besetzt. Von Seitenläppchen ist keine Spur vorhanden. Das am Ende verbreiterte 5. Tarsalglied zeigt, von der Seite gesehen, unten

1) Mochlonyx culiciformis, in: Dansk. Vid. Selsk. Skr., 1883, No. 1.

2) Dipterologia argentina: Culicidae. 
einen halbkreisförmigen Ausschnitt für die hier wenig entwickelte Streckplatte.

Blepharoceridae habe ich nicht untersuchen können. Nach Osten-SACKen ${ }^{1}$ ) giebt es in dieser Familie keine Pulvillen, während das Empodium (d. h. unser Sohlenläppchen) rudimentär ist. Sehr eigenthümlich sind die Krallen bei Hapalothrix lugubris Löw ơ, einer bis jetzt nur vom Monte Rosa ${ }^{2}$ ) und aus Steiermark ${ }^{3}$ ) bekannten Art. Nach der Abbildung Löw's sind sie hier in etwa länglich viereckige Scheibchen umgewandelt. Diese sind weich und haben die Function von Haftläppchen.

Auch bei den mir unbekannten Orphnephilidae ist das Sohlenläppchen rudimentär, mit kurzen Härchen besetzt, während die Pulvillen fehlen ${ }^{4}$ ).

Von den Simuliidae (Fig. 97-102) wird berichtet, dass ihre Füsse im Besitz von 3 Haftläppchen sein sollen. Da glaube ich aber, dass hierunter einige ganz andere Organe mitgerechnet sind, welche mir aber nur bei den Männchen vorzukommen scheinen. Die Weibchen zeigen nämlich (Simulia maculata MEIG. und meridionalis RILEY wurden untersucht) zweifelsohne nur einen kleinen „Haftlappen“, welcher mir durch das Empodium gebildet zu werden scheint; dasselbe ist hier sehr breit und unten behaart; die Härchen sind aber nicht geknöpft, also keine eigentlichen Hafthaare. Von den Pulvillen sind nur sehr unbedeutende Spuren vorhanden. Eigenthümlich ist der sehr tief gespaltene Vförmige Gelenkhöcker. Das 5. Tarsalglied ist an der Unterseite fast nicht ausgeschnitten. Die Krallen sind kurz und dick, mit einem grossen Zahn am innern Rande. Die Männchen von Sim. pictipes $\mathrm{H}_{\mathrm{AG}}$. (Fig. 93-102) zeigen nun überdies an jeder Kralle einen an deren Wurzel mit breitem Stiel befestigten Anhang, welcher fast schwarz gefärbt ist und am freien, zum 5. Tarsalglied hin schauenden Rande viele kleine Zähne aufweist, welche mit Querrippchen der Scheibe correspondiren. Was die Bedeutung dieser Apparate ist,

1) Contributions to the study of Liponeuridae, in: Berl. entomol. Zeitschr., V. 40, 1895, p. 153.

2) Löw, Revision der Blepharoceridae, in: Zeitschr. Entom. Breslau, (N. F.) Heft 6, 1877, p. 82 , tab. 1, fig. 8.

3) Strobl, Die Dipteren von Steiermark, in: Mitth. naturw. Ver. Steiermark, Jg. 1894 , p. 5.

4) Osten-SAcken, On the characters of the 3 divisions of Diptera: Nemocera vera, N. anomala and Eremochaeta, in: Berlin. entom. Zeitschr., V. 37,1892, p. 458. 
darüber lässt sich wenig Sicheres behaupten. Ein "Haftlappen“ ist es sicherlich nicht; eher wäre es etwa ein Reinigungsapparat.

Wie bekannt, findet man bei den Bibionidae entweder 3 gleiche Haftlappen (Bibioninae) oder nur einen (Scatopsinae) ; zunächst war zu untersuchen, ob es sich im letztern Falle vielleicht um 3 verschmolzene Haftläppchen handelt, wie behauptet worden ist. Da erwies sich aber sofort, sowohl bei Scatopse notata L. (Fig. 103) als bei Aspistes berolinensis Meig. (Fig. 104), dass auch hier 3 Haftlappen vorhanden sind; die beiden lateralen sind aber bloss viel kleiner als der mittlere (das Sohlenläppchen), wodurch sie bis jetzt übersehen wurden; auch sie aber sind im Besitz deutlich geknöpfter Hafthaare. Das 5. Tarsalglied ist unten stark ausgeschnitten. Am untern Ende desselben fand ich bei Scatopse keine Druckborsten; bei Dilophus (Fig. 105) sind sie klein. Hier findet sich aber unten am Praetarsus selbst zu beiden Seiten der Basis des mittlern Haftlappens eine lange Borste. Bei Bibio finden sich deren mehrere an der entsprechenden Stelle. Die Streckplatte ist zweireihig geriefelt.

Unter den Bibioniden soll Penthetria holosericea LATR. nur 2 Haftläppchen besitzen; ich habe mich aber überzeugen können, dass auch hier 3 Pulvillen vorhanden sind, aber besonders an den Mittelund Hinterbeinen ist der hintere bedeutend in der Entwicklung zurückgeblieben, so dass er mit der Lupe leicht übersehen wird.

Das Empodium von Rhyphus (Fig. 106) ist, namentlich am distalen Ende, sehr breit und mit vielen Hafthaaren besetzt. Die Stelle der Pulvillen wird nur durch längere Haare angedeutet. Das 5. Glied ist nach unten hin allmählich verkürzt.

Ueber die fernerhin zu den Orthorrhaphen gehörigen, meist grössere Thiere enthaltenden Familien habe ich nur wenig Neues mitzutheilen. Wie bekannt, besitzen die von Brauer als Platygenya homoeod a ctyla zusammengefassten Familien (Stratiomyidae, Xylophagidae, Tabanidae, Acanthomeridae, Leptidae, Acroceridae, Nemestrinidae) 3 gleiche Haftläppchen (Fig. 107-110). Wo ich sie untersucht habe, fand ich zwischen ihnen auch bei stärkerer Vergrösserung keine Differenzen; alle sind unten mit geknöpften Hafthaaren, oben mit kürzern, zugespitzten Haaren besetzt. Die Streckplatte pflegt feinkörnig zu sein. Druckborsten fand ich z. B. 2 bei Beris, mehrere, unregelmässig angeordnete bei Tabanus. Die Ventralseite des mittlern Haftlappens ist, so wie bei den so verschiedenartigen Sohlenläppchen der Nemocera, der unmittelbare Fortsatz der Streckplatte; derselbe ist also augenscheinlich mit diesen Sohlenläppchen homolog. 
Lampromyia, eine Leptide, besitzt nur 2 Haftlappen.

Bei den Platygenya heterodactyla (Mydaidae, Apioceridae, Asilidae, Bombyliidae, Therevidae, Scenopinidae) sind bald 2, bald 3 Haftlappen vorhanden, je nach der Beschaffenheit des Sohlenläppchens (Fig. 111-120). Dieses kann nämlich entweder den Seitenläppchen gleich gebildet sein, also selbst auch einen Haftlappen darstellen [Cyrtosia unter den Bombyliiden $\left.{ }^{1}\right)$ ], oder es ist schmal und dornförmig wie bei Asilus. Bald ist es hier nach oben umgebogen (As. trigonus Meig.), bald gerade (As. crabroniformis L.). Bei einigen Asilidengattungen, so bei Leptogaster (Fig. 118), Acnephalum, Rhadinus, Psilinus ${ }^{2}$ ), vermisst man beide Seitenläppchen. Das Homologon des Sohlenläppchens ist, wenigstens bei Leptogaster, krallenartig, nach unten gebogen. Die Strecksohle ist körnig. Bei wieder andern Platygenya heterodactyla ist das Sohlenläppchen verkürzt (z. B. Bombylius major L.; bei Hemipenthes morio L. ist es fast nur noch ein dreieckiges Läppchen). Bei Thereva, Mydas und Scenopinus fehlt das Sohlenläppchen ganz; es zeigt sich hier nur an der Stelle eine Wölbung mit etwas verdickter Chitinschicht.

Bei Thereva und Scenopinus fand ich die Seitenläppchen oben nur ganz wenig behaart; beide Gattungen besitzen 2 Druckborsten, welche namentlich bei Scenopinus lang sind.

Unter den Orthorrhapha orthogenya trifft man bei den Dolichopodidae (Fig. 120) schöne Beispiele von kammförmigen Sohlenläppchen (Psilopus, Argyra, Thinophilus, Dolichopus). Bisweilen, so bei Campsicnemus, ist das Sohlenläppchen breiter; bei Hydrophorus sieht es den seitlichen Haftlappen gleich. Das 5. Tarsalglied ist bei den Dolichopodiden unten nur wenig ausgeschnitten.

Grössere Verschiedenheit bieten die Empididae (Fig. 121, 122) dar. Hier ist das Sohlenläppchen bald schmal, unten kammförmig beborstet und so lang wie die Seitenlappen (Tachydromia cursitans F.), bald stachelartig, fast nackt, aber doch noch ziemlich lang (Cyrtoma spurium FALL., Fig. 121). Mehr in die Breite entwickelt zeigte es sich bei Hilara maura F. Dagegen fand ich kurze Sohlenläppchen bei Empis tessellata F. (Fig. 122) und Syneches muscarius F.; bei letzterer Art trägt es am Ende ein paar längere Haare. Bei mehreren Empiden kommen 2 Druckborsten vor. Nach der Abbildung von

1) Hier übertrifft es nach Perris' Figur, in: Ann. Soc. ent. France, V. 8, tab. 7, fig. h, selbst die Seitenläppchen an Grösse.

2) VAN DER WULP, Asilidae from Aden and its neighbourhood, in: Trans. ent. Soc. London, 1899 , p. 85. 
MıK ${ }^{1}$ ) hat auch Hilara sartor ein gut entwickeltes, "wie gefiedertes" Sohlenläppchen.

Was die ersten, aberranten Familien der Cy c lo r r hapha anlangt, so sind die Lonchopteridae (Fig. 123) und Platypezidae (Fig. 124) durch das Fehlen von Empodium und Sohlenläppchen ausgezeichnet (Lonchoptera lutea MeIG., Callomyia amoena MeIG., bei Platypeza fasciata F. ist das Empodium jeden Falls äusserst klein). Eigenthümlich ist bei Platypeza die Asymmetrie des 5. Tarsalgliedes, in dessen breitem Ende der kurze Praetarsus halb verborgen liegt.

Besser entwickelt ist das Sohlenläppchen bei Pipunculidae (Fig. 125). Bei Pipunculus sylvaticus MeIG. erreicht es jedoch noch nicht die halbe Länge der Nägel; es ist unbehaart, wie auch die Oberseite der Haftläppchen.

Während bei den vorher genannten Familien der Aschiza das 5. Tarsalglied unten am Ende einfach rund ausgeschnitten ist, findet sich bei Pipunculus hier ein Vorsprung, welcher 2 Druckborsten trägt. Dasselbe Verhalten kommt auch bei mehreren Syrphiden vor, mit welchen diese Familie überhaupt Verwandtschaft zeigt.

Bei den Phoridae (Fig. 126) ist der Sohlenfortsatz dornartig, stark nach oben umgebogen, nackt (Phora) oder an der Oberseite behaart (Trineura aterrima F.). Die Seitenläppchen sind bei Trineura von gewöhnlicher Form, bei Phora lang und schmal; von der Seite gesehen, erinnern dieselben hier sehr an das gekämmte Sohlenläppchen, wie es z. B. bei Chironomus vorkommt. Das 5. Tarsalglied ist an der Unterseite nur wenig verkürzt.

Vor einiger Zeit wurden von WANDOLLECK 3 flügellose Dipteren beschrieben ${ }^{2}$ ), welche dieser Autor in eine neue Familie (Stethopathidac) zusammenbrachte. Zwei dieser (nämlich Stethopathus ocellatus und eine noch nicht benannte Art) haben ein borstenähnliches, nacktes Empodium (wohl unser Sohlenläppchen) und sehr schmale, unten lang, aber sparsam behaarte Pulvillen, welche nach seiner fig. 10 fast den kammförmig behaarten Sohlenfortsätzen ähneln. Bei der dritten Art (Chonocephalus dorsalis) sind merkwürdiger Weise weder Pulvillen noch Empodium vorhanden. Diese interessanten Thiere, von welchen 2 zuerst von DAHL als die beiden Geschlechter seiner Puliciphora lucifera beschrieben und in verfehlter Weise als Bindeglied zwischen Dipteren und Puliciden betrachtet wurden, sind offenbar den Phoriden sehr nahe

1) in: Wien. ent. Zeitung, V. 13, 1894, tab. 2, fig. 10 u. 12.

2) Die Stethopathidae, eine neue flügel- und schwingerlose Familie der Diptera, in: Zool. Jahrb., V. 11, Syst., 1898, p. 412. 
verwandt. Мıк nimmt sogar keinen Anstand, sie letzterer Familie einzuverleiben.

Von den grössern Syrphidae (Fig. 127, 128) ist es schon seit Langem bekannt, dass das Ende der Füsse dasselbe Verhalten zeigt wie bei den schizophoren Cyclorrhaphen. Der Sohlenfortsatz ist hier ziemlich lang, nach dem Ende hin allmählich verdünnt, unten behaart. Die Pulvillen sind bei Eristalis z. B. an der Oberseite kurz und zerstreut behaart. Die betreffs der Stellung im System noch zweifelhaften Conopidae (Fig. 129) besitzen einen langen, nur an der Wurzel etwas behaarten Sohlenfortsatz; im Uebrigen schliessen sie sich den Schizophoren an. Für diese lässt sich das bekannte Verhalten von Musca domestica L. als Beispiel anführen; Vertreter der verschiedenen Familien dieser Abtheilung zeigten mir nur unbedeutende Abweichungen. So kann z. B. der Sohlenfortsatz bedeutend länger sein als die Pulvillen (Scatophaga stercoraria L.) und nur an der Wurzel behaart sein (Scatophaga stercoraria L., Tetanocera sylvatica MeIG., Borborus equinus FolL., Agromyza carbonaria Zeтt, Notiphila riparia Meig.). Bei Tachina larvarum L. ist er unbehaart, dagegen fand ich ihn z. B. bei Chlorops didyma ZеTт. (Fig. 130), Scatella stagnalis FALL. (Fig. 131), Asteia concinna Meig. bis zur Spitze behaart. Die Pulvillen sind an der Oberseite öfters nur an der Wurzel mit Härchen besetzt.

Relativ klein und schmal und viel kürzer als der Sohlenfortsatz sind die Pulvillen bei Scatella stagnalis FALL. Sehr gross sollen diese Organe dagegen nach GERcke ${ }^{1}$ ) bei einer Anthomyine (Hydrophoria wierzejskii Mıк) sein, namentlich an den Vordertarsen des Männchens. Die Krallen sind hier aber in der Regel nur als verkümmerte, behaarte Stummel vorhanden, indem sie leicht abzubrechen scheinen. In der Regel finden sich 2 Druckborsten am Ende des 5. Tarsalgliedes; bei Scatophaga stehen davor noch 2 eben solche Borsten. Sehr stark entwickelt sind die 2 Druckborsten bei Gastrophilus. - Gross ist der Praetarsus bei Pu pi p aren. Oefters ist hier der Basaltheil der Krallen sehr breit, so dass es einem Zahn ähnlich sieht und in den Beschreibungen auch als solcher angedeutet wurde. Der 3. Zahn bei Ornithomyia z. B. ist, wie auch OCKLer und SPEISER ${ }^{2}$ ) richtig bemerkt haben, eine solche „Basalplatte“. Das Sohlenläppchen kann, wie bei Ornithomyia, zweireihig gekämmt sein (Fig. 132).

1) in: Wien. entom. Zeitg., V. 8, 1889, p. 222, tab. 2, fig. 6, 7.

2) Eine neue, auf Halbaffen lebende Hippoboscidenart, ibid. V. 18, p. 201. 
Bei Lipoptena cervi L. ist der Praetarsus asymmetrisch, indem sowohl die Krallen als die Seitenläppchen an jedem Fuss ungleich gross sind; es steht hier das kleinere Läppchen an der Seite der grössern Kralle. Die Sohlenborste ist hier nur kurz behaart. Letztere fehlt bei Cyclopodia horsfieldi DE MeIJ., welche ich als Beispiel der Nycteribiiden untersucht habe. Die Seitenläppchen sind hier aber desto grösser (Fig. 133-135).

Wenn wir die verschiedenen Befunde bei den Dipteren zusammenfassen, so zeigt sich, dass auch hier der Praetarsus in unzweideutiger Weise als selbständiges Glied auftritt. Besonders deutlich ist dies auf Längsschnitten erkennbar. Diese lehren auch, dass die dorsale Medianpartie des Praetarsus, welche hier an der Wurzel meistens von dem letzten Tarsalglied überdeckt wird, in dieser Region öfters noch von einem Chitinstück gestützt wird. Namentlich das Empodium zeigte sehr verschiedenes Verhalten, indem es nur ausnahmsweise stark entwickelt und als Haftorgan von Nutzen ist (Tipuliden). Bei den meisten übrigen Dipteren ist es aber sehr zurückgebildet und nur auf Längsschnitten durch den Praetarsus genauer erkennbar. Dann tritt aber meistens an der Strecksohle ein Anhang auf, welchen wir im Allgemeinen als Sohlenfortsatz (Processus plantaris) unterschieden haben. In den vielen Fällen, wo derselbe lappenartig ist, möge ihm der Name Sohlenläppchen (Lobulus plantaris) beigelegt werden. Zwischen diesem lappenförmigen und dem dornförmigen Sohlenfortsatz finden sich alle Uebergänge, so dass wir diese verschiedenartigen Gebilde wohl alle als homolog betrachten dürfen, was bis jetzt, wie es namentlich von Osten-SACKen ${ }^{1}$ ) mit vollkommnem Recht betont wurde, noch fraglich war. Von den früber als Empodium zusammengefassten Gebilden ist aber das der Tipuliden den übrigen scharf gegenüber zu stellen.

Die Frage, wie man sich die Aufeinanderfolge der verschiedenen Zustände denken müsse, lässt sich meines Erachtens in folgender Weise beantworten. Zunächst ist als primitiver Zustand das kissenförmige, unterseits unbehaarte Empodium der Tipuliden zu betrachten. Diese Familie, wenngleich in verschiedener Hinsicht specialisirt, hat daneben so viel Primitives, wie z. B. die noch sehr verschiedenartige Nervatur, dass mir die Uebereinstimmung des Empodiums mit dem der verwandten Lepidopteren und Trichopteren wohl auf gemeinsamen

1) „Can a bristle be transformed into a pulvillus? It seems to me that the subject requires revision", in: Berlin. entom. Zeitschr., V. 37, 1892, p. 439, Anmerkung. 
Ursprung zurückführbar erscheint. Gerade in dieser Familie haben ja auch die Nebenläppchen, soviel bekannt, nie eine bedeutende Entwicklung erreicht.

Bei den Ptychopteriden kommt ein ziemlich entwickeltes Empodium vor, welches aber nicht als Haftorgan fungiren kann, indem gleich darunter sich ein scheibenförmiger Sohlenfortsatz befindet, welcher mit Hafthaaren besetzt ist.

Bei vielen Vertretern der primitiven Dipterenfamilien: Bibioniden (zumal Scatopsinen), Mycetophiliden, Cecidomyiden, Chironomiden (z. B. mehreren Ceratopogon) tritt dann der folgende Zustand auf: das Empodium hat sich dem Sohlenläppchen gegenüber ganz zurückgebildet. Dann folgen Zustände, wo auch die Seitenläppchen einen Besatz von Hafthaaren erwerben, wodurch sie für die Anheftung eine besondere Wichtigkeit erlangen und dann oft auch dem Empodium an Grösse wenig nachstehen. Solche, also mit 3 Haftläppchen versehene Dipteren findet man schon unter den unzweifelhaft sehr primitiven Bibioniden, ferner auch in der Mehrzahl unter den Orthorrhaphen-Brachyceren.

Ein höheres Verhalten hat sich nun dadurch entwickelt, dass durch die Vergrösserung der Seitenläppchen das Sohlenläppchen selbst als Haftorgan überflüssig wurde, und so tritt es denn in den höchsten Dipterengruppen (schon bei vielen Orthorrhaphen-Brachyceren und bei fast allen Cyclorrhaphen) als borstenartiges Gebilde auf, sei es an der Unterseite mit eigenthümlichen, kammförmig gereihten Haaren, sei es als sehr kurz behaarte Borste (Asilus, Eristalis); bisweilen ist es überhaupt nur als unbedeutender Fortsatz vorhanden oder fehlt auch ganz (Mydas, Lonchoptera, Platypeza). Es mag wohl ihre neue Function als Streckborste zu ihrer Erhaltung in vielen Fällen beigetragen haben.

In vereinzelten Fällen, z. B. bei Leptogaster, findet sich abweichende Entwicklung des Praetarsus als Begleiter (sei es als Ursache oder Folge) von eigenthümlichen Lebensverhältnissen.

Schliesslich mögen noch einige Worte dem Werthe des Praetarsus für die Systematik gewidmet sein. Es hat nämlich Osten-Sacken das Verhalten der Pulvillen als Kennzeichen für grössere Dipterengruppen angewendet. Indem er die $\mathrm{Nem}$ ocera in 2 Hauptabtheilungen spaltete, die Nemocera vera (Cecidomyidae, Mycetophilidae, Culicidae, Chironomidae, Psychodidae, Tipulidae?, Dixidae) und die Nemocera a nom a la (Bibionidae, Simuliidae, Blepharoceridae, Rhyphidae, Orphnephilidae), nahm er für die N. vera an, dass bei denselben niemals Seitenläppchen vorhanden sein sollten. Wir haben jedoch gesehen, dass in 
mehreren von den zu dieser Abtheilung gehörigen Familien (bei Cecidomyidae, Mycetophilidae, Culicidae, Chironomidae) diese Seitenläppchen ganz gut erkennbar sind und dass sie selbst bei vielen Chironomidae eine bedeutende Entwicklung erreichten, während hier đas Sohlenläppchen selbst zurückging; in diesen Fällen betrachtete OSTEN-Sacken die Seitenläppchen als ein zweilappiges Empodium. Es kommen also in beiden Abtheilungen OsTEN-SACKEN's die verschiedenartigsten Verhältnisse vor. Die Entwicklungsreihe, wie wir sie oben geschildert haben, hat jede Familie für sich, jeden Falls zum Theil, durchgemacht, und es haben Angehörige sehr verschiedener Familien das höchst entwickelte Stadium erreicht, so z. B. Chironomus, viele Asilidae, Dolichopus, Syrphidae, Muscidae u. s. w.

Die Fähigkeit, sich an den glatten Blattflächen festzuhalten und sich auch leicht wieder davon zu lösen, wurde also überall auf dieselbe Weise vervollständigt, während bei andern Insectenordnungen, z. B. Hemipteren, ganz andere Wege dazu eingeschlagen wurden. Es liesse sich dies auch dadurch ausdrücken, dass also den Dipteren im Ganzen eine bestimmte Variationsmöglichkeit inne wohnte, welche, sei es aus äussern, sei es aus innern Ursachen oder aus beiden zusammen, in Wirkung gesetzt, überall das gleiche Resultat hervorrief, trotz der doch sehr verschiedenen Körpergrösse und Körperform der Dipteren. Man vergleiche z. B. den schlanken Chironomus mit den plumpen echten Muscinen. Die Verschiedenheit in diesen Hinsichten war offenbar noch nicht im Stande, die Entwicklungsrichtung abzuändern. Nur sehr ausnahmsweise, wie bei Leptogaster, wurde ein neuer Weg betreten. Eine Hauptentwicklungsreihe aber, deren Eigenthümlichkeiten wohl viel mehr durch die den Dipteren inne wohnende Variationscapacität als durch die äussern Umstände bedingt wurden, lässt sich bestimmt nachweisen. Diese Hauptentwicklungsreihen kennen zu lernen und namentlich auch den Ursachen des Auftretens neuer Reihen nachzuspüren, ist eben eine der Aufgaben der neuern zoologischen Forschung.

Bevor ich zu den übrigen Arthropoden übergehe, mögen dem innern Bau des Praetarsus und seinem Gelenk noch einige Worte gewidmet sein. Dabei sei auf die verschiedenen Längs- und Querschnitte hingewiesen, welche zum Theil schon oben erwähnt wurden. Auf denselben zeigt sich zunächst der Gelenkhöcker (Gh Fig. 107, $111,112)$ als innerer Vorsprung der distalen abschliessenden Haut des letzten Tarsalgliedes. Auch hier liegt derselbe nicht an der Aussenfläche, sondern ist von derselben eine Strecke weit entfernt, 
während er nur dorsal mit der äussern Chitinhaut zusammenhängt (Fig. 117).

Es zeigt sich ferner, dass der Praetarsus nur an der Dorsalseite nicht in das letzte Tarsalglied eingezogen ist; an den Seiten und unten ist dies wohl der Fall. Besonders deutlich ist dieses Verhalten in Fig. 114. Es ist hierin ein mit Eau de Javelle durchsichtig gemachter Praetarsus von Asilus crabroniformis dargestellt. Die Lumina vom Praetarsus und vom letzten Tarsalglied stehen hier oben mit einander in Verbindung durch eine länglich viereckige Oeffnung, welche von den mit dickerer Chitinschicht bekleideten Streifen begrenzt wird.

Ein medianer Längsschnitt desselben Praetarsus findet sich in Fig. 111. Hier sei besonders auf den ins Innere vorspringenden Gelenkhöcker, dann auf das kleine Empodium und den darunter liegenden Sohlenfortsatz hingewiesen. In Fig. 107, welche sich auf Stratiomyia furcata bezieht und ebenfalls die Medianfläche darstellt, habe ich auch die Hypodermis eingezeichnet; dieselbe tritt hier nur mit einem unbedeutenden Vorsprung in den Praetarsus ein. Dieser Vorsprung hat $\mathrm{zu}$ beiden Seiten einen in je eine Kralle eintretenden Fortsatz, wie einer in Fig. 112, wieder von Asilus, dargestellt ist. In andern Fällen, so bei Eristalis, habe ich auch in der Wurzel von Seitenläppchen und Sohlenläppchen und im Empodium noch die Hypodermis finden können; auch $\mathrm{DAHL}^{1}{ }^{1}$ ) hat dieselbe in der Basis der Haftlappen von Sarcophaga beobachtet.

Noch mehr seitlich ist der in Fig. 113 dargestellte Längsschnitt gefallen. Es ist hier gerade die nach innen gewölbte Membran sichtbar, welche die seitliche Begrenzung des Praetarsus bildet. Noch weiter nach aussen fallende Schnitte zeigen den Praetarsus und das letzte Tarsalglied ganz von einander gesondert, wie in Fig. 128 von Eristalis. Es wurde hier der Praetarsus genau median durchschnitten, wie aus der Lage der Sehne erhellt. Oberseits fiel der Schnitt aber etwas mehr nach aussen durch die Wurzel der Kralle, und es zeigt sich hier schon gleich die selbständige obere Wand des Praetarsus, welcher von dem obern Theil des letzten Tarsalgliedes durch einen schmalen Zwischenraum getrennt erscheint. An der Stelle, wo die Trennung zwischen Praetarsus und letztem Tarsalglied eintritt, findet sich oft jederseits ein Chitinstreifen, welcher vorn mit dem Gelenkhöcker in Verbindung steht. Ihre Lage ist aus Fig. 114 ersichtlich; auch in Fig. 107 ist der

1) Die Fussdrüsen der Insecten, in: Arch. mikr. Anat., V. 25, 1885, tab. 12, fig. 12 .

Zool. Jahrb. XIV. Abth. f. Morph, 
Anfang von einem derselben als hinterer Anhang des Gelenkhöckers sichtbar. Mit der durch diese Streifen gebildeten Gelenkfläche articuliren die obern Enden der Seitenläppchen (Fig. 107, 114).

Von den Querschnitten Fig. 115 und 116 durch den Praetarsus von Asilus traf letzterer das proximale Ende der Streckplatte; es zeigt sich hier auch die Gleitfläche im Durchschnitt, dann der weite, obere Zusammenhang zwischen Praetarsus und letztem Tarsalglied. Das Verhalten mehr distalwärts ist in Fig. 115, links, dargestellt. Dieser Schnitt fiel vor der Gleitfläche, hat aber die Streckplatte getroffen und zeigt auch an der Seite der obern gemeinsamen Partie die oben erwähnten Chitinstreifen. Noch mehr nach dem Fussende hin liegt der rechts abgebildete Theil derselben Figur. Hier ist der untere Vorsprung des letzten Tarsalgliedes nicht mehr da, indem sich derselbe nicht so weit nach vorn erstreckt; die Chitinstreifen sind in dieser Region viel breiter.

Bemerkenswerth ist noch die eigenthümliche Faltung der Hypodermis (Fig. 115).

Dass die Hypodermis bei Hymenopteren und Lepidopteren oberhalb der Sehne, welche sich an die Streckplatte festsetzt, weit proximalwärts in das letzte Tarsenglied eingestülpt ist, wurde schon früher von $\mathrm{DAHL}^{1}$ ) nachgewiesen. Derselbe betrachtet diese Einstülpung als Drüse, welche das Secret für das Haftläppchen liefert.

Zur Vergleichung habe ich auch von den andern Gruppen der Arthropoden mehrere Vertreter der Untersuchung unterworfen.

Da sind zunächst die Myriopoden zu betrachten, und wohl an erster Stelle Scolopendrella (Fig. 136). Bekanntlich finden sich hier allein unter allen Myriopoden 2 Krallen, welche aber von ungleicher Grösse sind. Beide zusammen sind Anhänge eines Grundstücks und bilden mit diesem den Praetarsus. Ein Empodium ist nicht entwickelt, an ihrer Stelle finden sich ein paar feine Haare.

Bei den übrigen Myriopoden (Fig. 137) hat der Praetarsus im Ganzen die Form einer einzigen Kralle. Eine besondere Streckplatte ist noch nicht ausgebildet; das Glied ist überhaupt von den vorhergehenden Tarsalgliedern nur wenig verschieden. So wie bei Scolopendrella wird auch hier der Praetarsus bloss durch den Muskel bewegt, welcher an dem die Streckplatte entsprechenden Theil verbunden ist.

1) Die Fussdrüsen der Insecten, in: Arch. mikr. Anat., V. '25, 1885, p. 255. Man vergl. besonders tab. 13, fig. 19, welche das Verhalten bei Vespa darstellt. 
Die Arachniden zeigen sofort dadurch eine bedeutende Verschiedenheit, dass hier 2 Sehnen mit dem Praetarsus in Verbindung treten, eine ventrale und eine dorsale. Es möge als Beispiel Fig. 138, welche das Verhalten beim Scorpion vorstellt, angeführt werden. Die ventrale Sehne ist an einer oft schon gerippten Streckplatte angeheftet; eine Gleitfläche ist nicht entwickelt, und es bildet das Ende der Unterseite des letzten Tarsalgliedes überhaupt keinen Vorsprung. Für dieses von den Insecten abweichende Verhalten vergleiche man besonders Fig. 140 mit Fig. 111 und 112.

Besonders merkwürdig ist noch die Thatsache, dass die Krallen nicht mit dem letzten Tarsalglied gelenkig verbunden sind, indem hier der Gelenkhöcker gänzlich fehlt. Die Articulation findet sich eben im Praetarsus selbst, indem dieser im prominalen Theil einen starken Chitinring aufweist, welcher oben 2 laterale Gelenkhöcker für die Krallen trägt. Theils an diesem Chitinring, theils an der davor liegenden dünnern dorsalen Haut des Praetarsus ist die obere Sehne angeheftet. Die Krallen sind meist in der Zweizahl vorhanden.

Sehr verschiedenartig ist das Empodium, für welches in dieser Gruppe der Name „Pseudonychium" geläufig ist. Dieses ist mit dem oben beschriebenen Chitinring fest verbunden. Gerade bei den Scorpionidae ist der Praetarsus von bedeutender Entwicklung; er ist hier von den Seiten abgeplattet und fast ebenso hoch wie das vorhergehende Fussglied. Das Empodium sieht hier wie eine kleine Kralle aus.

Ganz dasselbe Verhalten findet sich bei den Pedipalpi wieder, wie die sich auf Thelyphonus beziehenden Abbildungen (Fig. 140, 141) zeigen.

Bei den Araneidae (Fig. 142-148) ist der Praetarsus sehr klein, sonst aber der Hauptsache nach gleich gebildet. Mehr in biologischer als in morphologischer Hinsicht von Bedeutung ist es, dass die Krallen und auch das Empodium meistens am untern Rand mit mehreren Zähnen besetzt sind, wie solche in der Abhandlung von OHLERT, „Beiträge zu einer auf die Klauenbildung gegründeten Diagnose und Anordnung der preussischen Spinnen" ${ }^{1}$ ), beschrieben und abgebildet sind.

Vielfach ist das Empodium gar nicht ausgebildet. Es kommt dann aber meistens zu beiden Seiten der Ventralhälfte des Praetarsus ein Büschel Borsten vor, welche am Ende kolbenartig erweitert zu

1) in: Verh. zool.-bot. Ges. Wien, 1854, p. 233. 
sein pflegen. Es sind dies in Chitinringen wurzelnde, je zu einer Hypodermiszelle gehörige Chitinhaare. Solche sind auch die als Vorkrallen (LEBERT) beschriebenen Anhänge des Tarsus, wie sie z. B. bei Epeira vorkommen, nur sind diese durch Grösse und die Entwicklung zahnartiger Vorsprünge ausgezeichnet, wodurch sie einigermaassen in ihrem Aussehen an die gezähnten Krallen erinnern; morphologisch sind sie davon aber ganz verschieden, können also auch nicht, wie es von Tuffen West behauptet und auch z. B. von Pagenstecher angenommen wurde, als Vorläufer der Krallen betrachtet werden. Sehr stark sind dieselben z. B. an den Hinterfüssen von Epeira (Fig. 148). Besondere Muskeln habe ich an denselben, entgegen Pagenstecher ${ }^{1}$ ), nicht beobachten können. In der Regel ist der Praetarsus bei den Spinnen weit in den vorspringenden ventralen Theil des Tarsus zurückgezogen.

Auch der mit einfacher Kralle versehene Praetarsus der weiblichen Kieferfühler steht mit 2 Sehnen, wie hier gewöhnlich, in Verbindung. Noch kommen hier gelegentlich, obgleich sehr selten, als Variation 2 Krallen vor, wie OHLERT einmal bei einem Xysticus fand; auch beobachtete er einen Fall, wo das Analogon der Kralle an einem männlichen Taster verdoppelt war ${ }^{2}$ ).

Ausnahmsweise kommt am Spinnenfuss auch ein Haftlappen vor; so nach Pagenstecher ${ }^{3}$ ) bei Attus phrynoides W., bei welchem die langen Vorderfüsse eine einzige, plumpe, aufgetriebene, nicht gezähnte Kralle mit einem Haftlappen haben.

Die Mehrzahl der Phalangidae (Fig. 149) trägt an den Füssen nur je eine Kralle. Auch diese obere steht hier mit 2 Sehnen in Verbindung, einer obern und einer untern. Ein besonderer Chitinring an der Basis des Praetarsus ist hier nicht erkennbar. Das ganze Glied bildet eine Kralle, welche nun aber, da mit dem Chitinring auch die Gelenkhöcker fehlen, mit 2 seitlichen Fortsätzen des distalen Endes des letzten Tarsalgliedes articulirt. Auch an der zuerst gebildeten embryonalen Cuticula fand ich den Praetarsus schon ganz gut entwickelt und von derselben Bildung wie beim erwachsenen Thier.

Der Praetarsus der Pseudoscorpionidae (Fig. 150) ist verhältnissmässig gut entwickelt. Ausser den 2 Krallen trägt er hier am Ende der Unterseite ein als Haftlappen fungirendes Empodium. In einem

1) Allgemeine Zoologie, V. 4, p. 406.

2) l. c. p. 236.

3) Allgemeine Zoologie, V. 4, p. 406. 
Beitrag zur Morphologie der Pedipalpi von LaUrie ${ }^{1}$ ), worin zugleich die Gliedmaassen der Arachnoiden unter einander verglichen werden, wird der Basaltheil des Praetarsus der Pseudoscorpioniden als sehr kleines, 7. Glied mitgezählt. In den Schemata der übrigen Arachnoiden dagegen hat dieser Autor meinen Praetarsus nicht als besonderes Glied angeführt. Am 1., die Scheere tragenden Fusspaar, ist der Praetarsus durch den beweglichen Finger vertreten.

In keiner Abtheilung der Arachnoiden zeigt das Endglied der Füsse so bedeutende Abänderungen wie bei den Acarinen (Fig. 151 -156). Noch am einfachsten dürfte es z. B. bei den Hydrachnen (Fig. 151) gebildet sein. Hier ist es überhaupt sehr klein, ganz an der untern Ecke des quer abgestutzten Tarsalgliedes angesetzt. Die 2 Krallen können nach oben geschlagen, in der halbkuglig ausgehöhlten Endfläche dieses Gliedes versteckt werden. Ein Empodium fehlt.

Etwas länger wird es bei Thrombidium (Fig. 152). Es findet sich hier schon im Anfang die Entwicklungsrichtung, welche für die Acarinen charakteristisch ist: Verlängerung des Praetarsus, während derselbe sehr dünn bleibt. Meistens geht damit in den extremern Fällen secundäre Gliederung gepaart. Bei einer Schildkrötenzecke (Amblyomma geayi Neum., Fig. 153) sind schon 2 solche secundäre Articulationen sichtbar.

Hinter der Krallenwurzel lässt sich auch hier ein Chitinstück beobachten, mit welchem die Krallen articuliren. Das Empodium ist hier breit, kissenförmig und als Haftorgan von Nutzen. In dieser Form kommt es bei vielen Acarinen, so z. B. bei vielen Gamasidae, vor, und es will mir scheinen, dass die Saugnäpfe der Acariden wohl oft durch Umwandlung des Empodiums geliefert werden. Nach Tuffen West ${ }^{2}$ ) kann dieser Haftlappen selbst in vereinzelten Fällen mit Hafthaaren bekleidet sein. Bei den Oribatidae dagegen ist das Empodium gewöhnlich krallenförmig. Mehrere Acarinen besitzen nur je eine Kralle an den Beinen (z. B. die Phytoptidae). Wenn nach Pagenstecher $^{3}$ ) die Gattung Heterotrichus an jedem Bein 14 Krallen aufweisen soll, so sind hier wohl krallenartige Haare gemeint, wie wir ihnen auch namentlich an Arachnidenfüssen öfters begegnen.

Schon seit längerer Zeit ist als besondere Eigenthümlichkeit des Fussendes der Solpugidae (Fig. 156-158) die Thatsache beobachtet, dass hier die Krallen selbst zweigliedrig sind. Im Uebrigen herrscht

1) Morphology of the Pedipalpi, in: Journ. Linn. Soc. London, V. 25,1896, p. 36

2 The foot of the fly, in: Transact. Linn. Soc., V. 23, 1862, p. 418.

3) Allgemeine Zoologie, V. 4, p. 403. 
auch hier das gewöhnliche Schema der Arachnoiden vor. Die obere Sehne ist an einem halbmondförmigen Chitinstück befestigt, mit welchem die Krallenwurzeln gelenkig verbunden sind. Nach unten hin geht dieser Halbmond jederseits in einen Chitinbogen über, welche zwei sich in der ventralen Medianlinie fast begegnen.

Gleich dahinter ist die Anheftungsstelle der untern Sehne.

Das Empodium zeigte sich bei der von mir untersuchten Art als grosser, unbehaarter, an der Spitze zweilappiger Haftlappen; in andern Fällen ist es viel tiefer gespalten, wie bei mehreren CeromaArten, wo die zwei Anhänge über den Krallen höchstens an der äussersten Basis zusammenhängen und sehr lang und schmal sind, zumal viel länger als die Krallen ${ }^{1}$ ). Es können aber bei Solpugiden auch diese Anhänge ganz fehlen, wenigstens an bestimmten Füssen. Auch in die Krallen tritt ein Tracheenast ein. An jeder Kralle ist die Spitze als besonderes Stück abgeschnürt und gelenkig mit dem längern, proximalen Theil verbunden. Es findet sich hierfür oberseits ein gefurchter Gelenkhöcker am Ende des letztern Theils.

An dem 3. Gliedmaassenpaar, welches bekanntlich den Kiefertastern ähnlich sieht, sind die Krallen sehr klein und eingliedrig. Nach Bernard ${ }^{2}$ ) findet sich an denselben, wie zu erwarten, eine obere und eine untere Sehne.

Ueber Limulus habe ich wenig mitzutheilen.

Die beweglichen Finger an den Scheerenfüssen sind mit je 2 Sehnen verbunden. Dasselbe ist der Fall mit dem Endglied des 6., keine Scheere tragenden Extremitätenpaares.

Das 5. Glied derselben trägt 4 lamellenförmige Anhänge, das 6 . deren einen, welcher mehr zugespitzt ist; alle diese sind aber nur passiv beweglich. Das letzte Glied zeigt bei Limulus überhaupt nichts Besonderes; es verjüngt sich einfach nach der Spitze hin.

Der letzte Beinabschnitt der Crustacea ist, wenigstens in den höhern Abtheilungen, als Dactylopodit bekannt. Wie bei den Arachnoiden, sind am proximalen Ende 2 Sehnen angeheftet, eine untere und eine obere. Letztere liegt aber meistens, im Zusammenhang mit der schief gestellten Articulationsebene, mehr oder weniger an der Seite des betreffenden Gliedes.

Das Ende dieses Dactylopoditen verdient noch eine genauere Be-

1) Vergl. Purcell, New and little known South-African Solifugae, in: Ann. South-African Mus., V. 1, p. 396, fig. 13b.

2) Comparative morphology of Galeodidae, in: Trans. Linn. Soc. London, 1896, p. 334. 
trachtung. Untersucht man dasselbe z. B. bei Idotea (Fig. 159-162), so ergiebt sich, dass das Dactylopodit sich nicht einfach in die sogenannte Endklaue zuspitzt, sondern dass letztere durch ein besonderes Gelenk mit dem vorhergehenden Theil verbunden ist. Da zugleich in die Kralle ein bedeutender Theil der Matrix hineintritt, so will es mir scheinen, dass auch hier diese Kralle nicht einem Haare oder einer Borste homolog zu setzen sei, sondern dass sie als abgeschnürter Theil des Dactylopoditen zu betrachten sei, welche somit hier secundäre Articulation zeigt.

Besser entwickelt ist dieses Verhalten noch bei den Onisciden. Es findet sich hier unterseits am Ende der ersten Partie des Dactylopoditen ein langer Dorn, welcher fast das Ende der Kralle erreicht. Bei mehreren Sphäromiden ist an derselben Stelle ein dicker, zahnartiger Vorsprung zu beobachten. Wenn Gerstaecker in: Bronn's Thierreich ${ }^{1}$ ) angiebt, dass hier die Endklaue unten einen Zahn trägt, so lässt sich hinzufügen, dass hier dieser Zahn nicht an, sondern vor der beweglich eingelenkten Endspitze wurzelt.

Noch eigenthümlicher entwickelt ist das letzte Fussglied bei Jaera albifrons LeACH (Fig. 165, 166). Es ist dasselbe hier ziemlich kurz und breit; die Kralle selbst ist klein, nach unten gebogen. Ausserdem finden sich nun hier aber vor der Kralle, an der Oberseite 2 krallenartige Anhänge, welche mir nicht etwa grosse Borsten, sondern echte Hypodermisfortsätze zu sein scheinen. Es sind hier also nicht 2, wie GERstäckeR ${ }^{2}$ ) angiebt, sondern 3 krallenartige Organe vorhanden. Nach diesem Autor soll auch bei Janira und Munna derartiges vorkommen.

Ein Beispiel geringerer Entwicklung des Endtheils zeigt Asellus (Fig. 164). Hier ist an der Oberseite die Klaue nicht einmal durch ein Gelenk, sondern fest mit dem vorhergehenden Theil verbunden. Dasselbe findet sich noch in grösserm Maasse bei Gammarus (Fig. 167).

Auch bei den Decapoden lässt sich die Klaue am Dactylopoditen noch wiederfinden, wenngleich sie hier sehr reducirt ist. So zeigt sie sich am 2. Fusspaar von Astacus fluviatilis als kurzer, dicker, gelber Zahn. Auch die vorspringende ventrale Endpartie des Dactylopoditen ist intensiv gelb gefärbt.

Es liegt nun, wenn überhaupt eine Vergleichung der Beinabschnitte der Crustaceen mit denen anderer Arthropodengruppen zulässig ist,

1) V. 5, Abth. 2, Isopoden, p. 31.

2) l. c. p. 31. 
wofür meines Erachtens trotz aller Verschiedenheit doch das viele Gemeinsame wohl ein Recht giebt, die Frage nahe, was nun hier mit dem Praetarsus homolog ist. Da haben wir nur die Wahl zwischen dem Dactylopoditen und der Klaue selbst. Haben wir es hier mit einem 2 gliedrigen Praetarsus zu thun, oder ist die Klaue allein mit dem Praetarsus zu vergleichen, während der übrige Theil des Dactylopoditen noch einen Abschnitt des Tarsus darstellt? Da meine ich, dass das Verhalten der Sehnen bestimmt zu Gunsten der erstern Auffassung spricht. Die Uebereinstimmung mit den Arachnoiden in dieser Hinsicht ist so gross, dass wir auch hier in dem ganzen, auf den Anheftungspunkt der Sehne folgenden Theil den Praetarsus erblicken dürfen. Dieser ist dann also hier secundär 2 gliedrig, in einer Weise, wie es sonst bei den Arthropoden nicht vorkommt. Denn das dorsale Gelenk am Praetarsus vieler Arachnoiden ist an der Ventralseite gar nicht angedeutet, und bei den secundären Gliederungen der Acarinen ist gerade der an der Sehnenanheftung vorangehende Theil verlängert und in verschiedene Abschnitte getheilt.

Besonders interessirten mich auch die Pycnogonidae (Fig. 168 bis 170). Gerade in neuester Zeit wurde auf die Bildung des Endabschnitts der Beine in dieser Gruppe wieder einmal besonders hingegewiesen. Meinert ${ }^{1}$ ) hat nämlich bemerkt, dass die zwei hier an dem klauenförmigen Endglied an der Wurzel oberseits vorkommenden krallenförmigen Gebilde zu vergleichen seien mit den echten Krallen der Arachnoiden und Insecten, Gebilde, welche bei den Crustaceen fehlen. Es wird dies von ihm als neues Argument für die Arachnoidennatur der Pycnogoniden angeführt. Es heisst nämlich in seiner Abhandlung: „These auxiliary claws [d. h. die 2 kleinen Krallen] are really the terminal claws of the foot, originating from and attached to the last joint (the claw) of the foot. In so far they are real claws, and correspond to the claws in the Arachnoids and most Insects; corresponding claws are wanting in the Crustacea, and therefore their presence in the Pycnogonida is of no small systematic importance." Die grosse Klaue selbst ist nach ihm ,only the last terminal joint of the leg (corresponding to the claw in the larva of the Staphylinids and of most Coleoptera)". Meinert macht also einen Unterschied zwischen der Kralle letzterer Insecten und den 2 gewöhnlichen Insectenkrallen.

Was nun die Anwesenheit der 2 kleinen Krallen betrifft, so meine

1) in: The Danish Ingolf-Expedition, V. 3, 1899. 
ich, dass Meinert dieser in so fern zu viel Bedeutung zuschreibt, als wir auch bei den Crustaceen derartigen Gebilden begegnet sind. Es waren doch auch am Praetarsus von Jaera 2 Anhänge vorhanden, welche sich als Krallen deuten liessen. Es liesse sich also ganz gut vorstellen, dass, auch wenn die Pycnogoniden den Crustaceen sehr nahe ständen, sich eben solche Krallen secundär entwickelt hätten, wie es auch bei den genannten Isopoden der Fall ist.

Da sich in DoHRN's Monographie dieser Gruppe ${ }^{1}$ ) schon eine eingehende Beschreibung des Gelenks an der Basis 'der Endklaue findet, möge hier als Beispiel das Verhalten bei Nymphon grossipes F. (Fig. 168-170) näher erörtert werden. Der Praetarsus ist hier relativ lang. Unterseits ist an der Wurzel keine besondere Streckplatte entwickelt, sondern es setzt sich hier die Medianpartie dieses Gliedes unmittelbar in die Sehne fort, welche auch, aber für einen geringen Theil, von einem Fortsatz des eingeschlagenen Ventralendes des vorletzten Beingliedes geliefert wird. Auch an der Oberseite findet sich eine Sehne, welche an einem Chitinhöcker endet. Dieser Höcker bildet die mittlere Partie eines Chitinhalbrings, welcher jederseits mit dem stark chitinisirten Hinterrand der Kralle in Verbindung steht. Die Kralle hat nämlich zu beiden Seiten einen Fortsatz, welcher mit einem eben solchen, der sich an der Seite des letzten Beingliedes findet, articulirt. Oberseits bleibt zwischen dem erstgenannten Halbring und dem Hinterrand der Kralle eine membranöse Partie übrig, welche die beiden Krallen (Nebenkrallen) trägt. Namentlich bei mehreren Nymphon-Arten erreichen dieselben eine bedeutende Entwicklung, sie bleiben aber meistens kürzer als die Klaue selbst. Die Anordnung der 2 Krallen zusammen auf einer membranösen Partie spricht wieder bestimmt gegen die Auffassung derselben als modificirte Borsten. Vergleicht man das Verhalten bei Nymphon mit demjenigen, was wir bei andern Arthropoden gefunden haben, so zeigt sich noch am meisten Annäherung an die Arachnoiden. Namentlich die Anheftung der obern Sehne und die Anordnung der Krallen spricht dafür, ebenso jegliches Fehlen einer secundären Gliederung des Praetarsus, wie dasselbe bei den Crustaceen so oft gefunden wird.

Bei einigen Pycnogoniden, so z. B. bei Pycnogonum littorale, findet sich von den Krallen und auch von der membranösen Stelle, auf der dieselben zu stehen pflegen, keine Spur. Es liesse sich fragen, ob dies ein secundäres oder primitives Verhalten wäre. Obwohl mir

1) Die Pantopoden des Golfes von Neapel, 1881, p. 25-27. 
hierauf zur Zeit keine bestimmte Antwort zu geben zu sein scheint, will es mir doch vorkommen, dass die Annahme, es seien in dieser Gruppe die Krallen in der Rückbildung begriffen, die richtige ist. Ueberhaupt hat das Auftreten der Nebenkrallen hier in ihrem meistens bedeutendem Zurücktreten der grossen Klaue gegenüber, wenn man dieses Verhalten mit dem gewöhnlichen Zustand bei den Arthropoden vergleicht, das Gepräge von etwas Rudimentärem, und was z. B. Pycnogonum littorale anlangt, so sind die besten Kenner dieser Gruppe darüber einig, dass diese Gattung wohl eine der am meisten modificirten darstellt.

Für diese Frage scheint es mir auch besonders wichtig, dass wenigstens eine Pycnogonide bekannt ist, wo die Hauptkralle von den Nebenkrallen an Länge weit überragt wird. Ueber dieses Verhalten theilt DoHrn Folgendes mit: „Als sehr auffallende Ausnahme ist der Befund bei Ammothea biunguiculata zu erwähnen, bei welcher die Hauptkralle gänzlich rudimentär geworden ist auf Kosten der stärker entwickelten Nebenkrallen. Es ist mir nicht gelungen, über ihre Function irgend welche Beobachtung zu machen, so bin ich denn auch nicht im Stande, für die Verschiedenheit ihrer Ausbildung irgend welchen Grund anzudeuten"1). Die bezüglichen Figuren (tab. 8, fig. 2 u. 3) zeigen eine auffallende Aehnlichkeit mit einem Arachnoidenpraetarsus. Ich möchte denn auch der Ansicht sein, dass wir es hier wohl mit einem primitiven Verhalten zu thun haben; wenigstens scheint mir diese Annahme ebenso gerechtfertigt zu sein wie die entgegengesetzte DoHRs's, dass hier die Hauptkralle gänzlich rudimentär geworden sei. Merkwürdiger Weise fehlen bei einer andern Art derselben Gattung (Ammothea uniunguiculata) gerade die Nebenkrallen.

Aus dem Obenstehenden erhellt, dass ich mich denjenigen Forschern anschliessen möchte, welche die Kralle der Pycnogoniden als 9. Beinglied auffassen. Besonders die active Beweglichkeit mittels der beiden Sehnen scheint mir hier von entscheidender Wichtigkeit zu sein, dann auch die vergleichend anatomischen Verhältnisse. Die Aehnlichkeit zwischen Haupt- und Nebenkrallen ist immerhin nur eine äussere und ist auch durchaus nicht befremdend, indem alle die 3 Krallen nach meiner Auffassung die Endspitzen eines einzigen Gliedes darstellen. An der Wurzel dieses Gliedes inseriren sich die Sehnen. Die mehr oder minder passive Beweglichkeit der Nebenkrallen thut hier nichts zur Sache.

1) Die Pantopoden des Golfes von Neapel, p. 26; man vergl. auch p. 105 . 
Dass bei Pallene phantoma DoHRN ,die Nebenkrallen an der Basis mitunter noch 2-3 kleinere, senkrecht auf sie gestellte Dornen tragen"1), wäre auch für unsere Ansicht als Argument anzuführen, wenn es sich hier wirklich um stärkere Haare handelte; es scheint dies nach Dohrn's Figur (tab. 14, fig. 3) wohl der Fall zu sein, doch bin ich darüber nicht sicher, weil die betreffenden Gebilde auf p. 185 von diesem Autor als secundäre „Krallen“ beschrieben werden.

Es bleibt nun noch die Gattung Peripatus (Fig. 171-174) mit Hinsicht auf unser Thema zu untersuchen. Gerade der Umstand, dass schon seit Langem die Anwesenheit von Krallen bei diesen Thieren als von grosser Bedeutung erachtet wurde, so sehr, dass der Name der ganzen Gruppe Onychophora diesem Kennzeichen entnommen wurde, macht es interessant, das Verhalten dieser Krallen mit denjenigen anderer Arthropoden zu vergleichen. Bekanntlich besteht jede Extremität bei Peripatus aus zwei Theilen, von welchen der proximale als Bein, der distale als Fuss unterschieden wird. Beide Theile sind durch ein dünnes Verbindungsstück mit einander verbunden. Es zeigt sich nun, dass der Fuss mit 2 Spitzen endet, in welche sich auch die Matrix fortsetzt, welche aber besonders dadurch ausgezeichnet sind, dass hier die Chitinschicht eine bedeutende Entwicklung erlangt hat. Diese Spitzen sind eben die beiden Krallen. Es leuchtet somit ein, dass auch hier die Krallen zunächst als Wucherungen oder Ausstülpungen der Hypodermis aufzufassen sind, ohne irgend welchen $\mathrm{Zu}$ sammenhang mit Haaren oder Borsten, welch letztere Gebilde denn auch bei Peripatus ganz fehlen, wenigstens in dem Sinne, wie sie bei den andern Arthropoden gefunden werden, denn die Chitinstifte auf den primären Papillen BALFOUR's ${ }^{2}$ ) sind nach den Mittheilungen dieses Forschers ganz anderer Natur. Es stimmen somit die Krallen in dieser abweichenden Gattung ganz mit denjenigen anderer Arthropoden überein, was die morphologische Bedeutung anlangt. Gerade weil hierin die Arthropoden unter einander verschieden sind, interessirte mich besonders die Anheftungsstelle der bezüglichen Muskeln. Längsschnitte durch den Fuss zeigten nun, dass der einzige, hier in Betracht kommende Muskel mit dem obern Theil der Krallenwurzel in Verbindung steht und auch im Beinglied dicht an der Oberseite zu verfolgen ist. Dieser Muskel findet sich auch in BALFour's fig. 20, tab. 18, seine Anheftungsstelle ist hier aber nicht präcis genug ange-

1) Dohrs, Die Pantopoden des Golfes von Neapel.

2) The anatomy and development of Peripatus capensis, in: Quart. Journ. microsc. Sc., (N. S.) V. 23, 1883, p. 213. 
geben, indem sich nur im Allgemeinen daraus entnehmen lässt, dass derselbe nach den Krallen verläuft. Es zeigt sich somit die wichtige Thatsache, dass Peripatus in dieser Hinsicht sich von allen Arthropoden unterscheidet, da bei Crustaceen und Arachnoiden auch immer ein unterer Muskel vorhanden ist, während bei den Insecten und Myriopoden gerade der obere Muskel fehlt.

Der Theil der Extremität, von welchem die Krallen unmittelbare Anhänge sind, d. h. also der sogenannte Fuss, lässt sich hier meines Erachtens als Praetarsus deuten. Allen übrigen Abschnitten der Beine homolog würde dann hier der noch ganz undifferenzirte proximale Theil sein.

Wie Fig. 174 zeigt, wird die Wurzel der Kralle von einem Hautlappen überdeckt, welcher wohl dadurch besonders stark erscheint, weil hier die Krallen in zurückgezogenem Zustand fixirt wurden.

Es möge hier nun zunächst eine kurze Zusammenfassung der Hauptbefunde folgen.

Wenn wir hierbei mit den Crustaceen anfangen, so finden wir hier das letzte Beinglied, wenigstens in den höhern Abtheilungen, als meist bedeutend entwickelten Dactylopodit. In den niedern Abtheilungen ist die Zahl der Beinglieder überhaupt sehr schwankend und das letzte Glied nicht besonders differenzirt.

Der Dactylopodit wird von einem obern und einem untern Muskel bewegt; sehr oft ist der distale Theil durch eine secundäre Articulation mit dem proximalen Theil verbunden. Es ist hierbei aber bloss eine passive Bewegung möglich, denn besondere Muskeln fehlen. Diese Articulation ist wohl bloss dadurch von Nutzen, dass nun das Abbrechen der Spitze weniger leicht geschieht.

Nur ausnahmsweise, z. B. bei Jaera, Janira, Munna, kommt es zur Ausbildung von krallenartigen Anhängen, welche dann dem proximalen Theil des Dactylopoditen ansitzen.

Bei Limulus ist das Endglied ebenso einfach wie bei den Crustaceen und zeigt selbst keine Spur secundärer Articulation.

Auch bei den Arachnoiden finden sich 2 Sehnen, eine obere und eine untere, am Endglied (Praetarsus) verbunden. Die 2 Krallen sind bier deutlich als directe Fortsätze, Wucherungen dieses Gliedes selbst erkennbar. Sie articuliren mit je einem Gelenkhöcker, welcher einem proximalwärts im Praetarsus liegenden Halbring angehört. Es ist also auch hier eine secundäre Articulation vorhanden, welche aber, 
anders als bei den Crustaceen, nur an der Oberseite vorhanden ist und unmittelbar auf die Sehne folgt. Das Empodium ist vielfach krallenartig, zeigt sich aber doch auch oft als Haftapparat. Bei den Acarinen hat die secundäre Articulation in ausgedehnter Weise stattgefunden.

Die Pycnogoniden zeigen im Allgemeinen den Charakter der Arachnoiden. Nur sind hier die Krallen meistens verhältnissmässig klein oder fehlen bisweilen ganz. Doch ist in vereinzelten Fällen gerade die Hauptkralle sehr klein, während die Nebenkrallen stark entwickelt sind.

Bei den Myriopoden und Insecten finden wir sehr einfache, in mehreren Fällen aber wohl durch Reduction entstandene $\mathrm{Zu}$ stände da, wo nur eine Kralle vorhanden ist. Es ist dies der Fall bei allen Myriopoden (ausser Scolopendrella), bei Pediculiden, Poduriden, vielen Mallophagen, bei Cocciden, Bittacus, Hybusa (Orthoptera) und Pselaphiden und einigen andern Coleopteren und unter den Hemipteren bei Belostoma (Vorderfüsse), ferner bei den Larven der metabolen Insecten (ausgenommen die Larven der meisten Carabiden, Dytisciden, Gyriniden und Neuropteren) ${ }^{1}$ ). Da stellt die Kralle selbst fast das ganze Endglied dar. Die Gelenke können mehr oder weniger differenzirt sein; bei Pediculiden haben sie z. B. eine hohe Stufe erreicht. Letzteres ist auch meistens bei den zweikralligen Insectenfüssen der Fall. Es lassen sich hier die Streckplatte, die Gleitfläche und oft auch die zwischen Streckplatte und Empodium liegende Strecksohle deutlich erkennen. Wie auch beim einkralligen Insectenfuss, findet die dorsale Articulation durch einen besondern Höcker des letzten, also dem Praetarsus vorangehenden Tarsalgliedes statt. Es findet sich bei allen Insecten und Myriopoden bloss die an der Streckplatte endende Sehne.

Das sehr verschiedenartig entwickelte Empodium trägt mit den vielfach vorhandenen Seitenläppchen (Lobuli laterales) zur Complicirung des Praetarsus bei. Mehrmals haben sich auch besondere Läppchen unter der Krallenwurzel entwickelt, welche wir als Krallenläppchen (Lobuli unguiculares) unterschieden haben.

Was Peripatus anlangt, so zeigte sich hier die merkwürdige Thatsache, dass derselbe mit den Insecten darin übereinstimmt, dass nur ein einziger Muskel für das Endglied da ist, sich von denselben aber unterscheidet durch die dorsale Lage dieses Muskels.

1) Kolbe, Einführung in die Kenntniss der Insecten, p. 285. Wenn BraUer bezüglich der Larve von Panorpa communis L. bemerkt, dass er hieran keine Krallen bemerken konnte, so ist hier wahrscheinlich der Praetarsus ganz den übrigen Gliedern gleichartig. 
Es möge jetzt über di e Natur der Krallen einiges gesagt werden. Da scheint es mir zunächst unabweisbar, dass dieselben nur directe Fortsätze, Wucherungen der ganzen Haut des Praetarsus sind, also nicht homolog mit Haaren oder Borsten. Letztere gehören je einer einzigen Hypodermiszelle an, erstere können noch eine Anzahl Hypodermiszellen in ihrem Innern beherbergen. Es scheinen mir zunächst folgende Gründe für diese Ansicht zu sprechen: Zunächst lässt sich dieses Verhalten in vielen Fällen, so z. B. schon bei Peripatus, direct beobachten. Sie sind hier, wie gewöhnlich an der Innenseite, mit einer Hypodermisschicht bekleidet und communiciren durch eine weite Oeffnung mit dem übrigen Theil des Praetarsus. Dann sind öfters selbst Tracheen in der Kralle nachweisbar (z. B. sehr schön bei Pediculus). Ferner können die Krallen selbst wieder echte Haare oder Borsten tragen. Es kommt dies namentlich bei vielen Hymenopteren vor, jedoch auch bei Orthopteren, Hemipteren. Bisweilen sind die Krallen an der Wurzel verwachsen (z. B. bei mehreren Curculioniden), was auch bei echten Haaren nicht beobachtet wird. Während starke Borsten in einem Chitinring eingepflanzt zu sein scheinen, ist dies mit den Krallen nicht der Fall. Die Krallen haben also mit den Haaren nichts $\mathrm{zu}$ thun, wenn man wenigstens mit letzterm Namen nicht alle langen, spitzen Anhänge bezeichnen will. Dann ist es aber gar kein morphologischer Begriff.

Es liesse sich nun fragen, wie die Krallen entstanden sind. Es sind da zwei Ansichten möglich. Entweder hat das Endglied sich am Ende gespalten, oder es entstehen die Krallen als dorsale Anhänge vor der Spitze des Endglieds. Es leuchtet ein, dass bei ersterer Auffassung der zweispitzige, bei letzterer der dreispitzige Zustand des Praetarsus der primitivste ist. Es scheint mir schwer, für die eine oder andere Ansicht entscheidende Beweise anzuführen. Für die Spaltung spricht einerseits das Verhalten bei Peripatus, wo von einer 3. Spitze, welche dann also das Empodium darstellen würde, keine Spur vorhanden ist, andrerseits auch der Umstand, dass bei den Insecten sich keine Fälle finden, wo die Krallen sich als kleine Anhänge am Praetarsus zeigen. Bei den Metabolen zeigt sich z. B. die directe Umwandlung vom einkralligen Fuss in den zweikralligen, letzterer oft ohne Spur eines Empodiums.

Die einzigen Thatsachen, welche mir für die andere Auffassung zu sprechen scheinen, sind die Verhältnisse bei einigen Isopoden und bei den Pycnogoniden. Bei Jaera sind die Krallen wohl ohne Zweifel als dorsale Anhänge entstanden, wie der normal vorhandene, hier secundär abgegliederte distale Theil des Dactylopoditen lehrt. Letzterer wird 
hier also gewissermaassen zu einem Empodium. Auch bei den Pycnogoniden haben die Krallen das Ansehen secundärer Anhänge, doch haben wir es hier wohl mit Rückbildungszuständen der Krallen zu thun. Es ist auch nicht unmöglich, dass die Krallen bei den Branchiaten (vielleicht + Arachnoiden) auf die eine, bei den übrigen Tracheaten auf die andere Weise entstanden sind.

Mit letzterer Frage hängt die Bedeutung und die primitive Form des Empodiums unmittelbar zusammen. Bei der Spaltungsannahme fehlt das Empodium nämlich zunächst ganz, bei der andern ist es von vorn herein als die primäre Endspitze des Praetarsus vorhanden. Es zeigt sich nun wenigstens, dass das in letzterm Falle primitive, krallenartige Empodium bei den Insecten sehr selten ist; es findet sich z. B. bei Lepisma, einigen Coleopteren, unter den Dipteren bei Leptogaster. Auch bei Scolopendrella und bei Insectenlarven fehlt das Empodium. Bei den Arachnoiden dagegen ist das Empodium oft krallenförmig.

Es lässt sich also vermuthen, dass bei den Insecten wenigstens das Empodium erst secundär eine stärkere Entwicklung erreicht und sich da zunächst zu einem Haftkissen entwickelt hat. Als solches kommt es bei einigen Dermapteren, bei Plecopteren, bei vielen Orthopteren, bei Thysanopteren, Neuropteren, Panorpaten, Hymenopteren, Trichopteren, Lepidopteren und unter den Dipteren bei den Tipuliden vor. Bei stärkerer Entwicklung wird es von besondern Chitinringen gestützt. Die Unterseite ist in allen diesen Fällen unbehaart.

Bei weitaus den meisten Dipteren ist von dem Empodium nur noch ein Rudiment übrig geblieben und dessen Function oft von einem besondern Fortsatz der Strecksohle (dem Sohlenläppchen) übernommen. Daneben sind dann in vielen Fällen die Seitenläppchen stark entwickelt; alle diese Läppchen tragen an der Unterseite einen dichten Besatz von Hafthaaren. Namentlich die höchst stehenden Dipteren haben als Haftapparat nur die Seitenläppchen bewahrt, indem der Sohlenfortsatz borstenähnlich wurde. Ich will hier noch bemerken, dass Ockler unter dem Namen Streckborste zweierlei Organe zusammenfasst: zunächst das schmale Empodium, wie es z. B. viele Coleopteren aufweisen, dann aber auch den borstenartigen Sohlenfortsatz vieler Dipteren.

Bei mehreren Coleopteren und Hemipteren tritt die unterseits an die Krallenwurzel grenzende Membran mehr oder weniger lappenartig hervor. Namentlich bei den Hemipteren sind diese Krallen-Haftläppchen oft sehr gross. Es kann hierbei die Ventralseite der Kralle mehr oder weniger mit in den Haftlappen aufgenommen werden, so 
dass im extremsten Fall die Kralle selbst in einen Haftlappen umgebildet wird, welcher nur noch oberseits Spuren starker Chitinisirung zeigt. Das findet sich bei mehreren Hemipteren, bei einigen Coleopteren (z. B. einige Krallen von Psilothrix nobilis GruH.), bei vielen Krallen von Ephemeriden und vereinzelt bei Dipteren (bei dem Liponeuriden Hapalothrix lugubris I.öw.).

Von Seitenläppchen finden sich in den niedern Insectenordnungen entweder keine oder nur sehr geringe Spuren. Bei einigen Neuropteren sind sie etwas besser entwickelt, treten aber bei den Trichopteren, Lepidopteren und Dipteren in voller Entfaltung auf. In den zwei erstgenannten Gruppen sind sie in der Regel gross, und wenn sie bei Lepidopteren z. B. fehlen, dürften sie wohl rückgebildet und schliesslich verloren gegangen sein. Für Papilio lässt sich z. B. schwer behaupten, dass das Fehlen der Seitenläppchen ein primitives Verhalten sei. In diesen zwei Gruppen sind sie in gleicher Weise entwickelt, sie bilden flache, am Rande mehr oder weniger in Fetzen getheilte oder grössere Einschnitte zeigende Läppchen, welche GrabER und OckLER als Greiforgane betrachten, indem sie mit ihren Härchen zwischen denen der Pflanzen haften. Bei den Dipteren scheint sich die Sache etwas anders $\mathrm{zu}$ verhalten. Hier sind sie bei vielen Vertretern der niedrigsten Familien, so bei allen Tipuliden, sehr winzig, und es liegen keine Gründe vor, hierbei etwa Rückbildung in Anspruch zu nehmen. Bei vielen höhern Dipteren sind sie auf Kosten des Empodiums weiter entwickelt und tragen dann an ihrer Unterseite einen dichten Besatz von Hafthaaren.

Man muss sich also bei der gemeinschaftlichen Stammform der immerhin verwandten Ordnungen der Trichopteren, Lepidopteren und Dipteren einen indifferenten Zustand denken, mit noch unbedeutenden Seitenläppchen, aus welchen sich einerseits die als Greiforgane fungirenden Läppchen, andrerseits die Haftläppchen der Dipteren entwickelt haben.

Auch bei einigen Coleopteren, so namentlich bei Meloiden, kommen Seitenläppchen vor, welche hier, wie bei Meloe selbst, das Aussehen von Krallen annehmen können.

Dass viele einfach gebildete Prätarsen durch Rückbildung verschiedener Theile entstanden sind, dafür lassen sich viele Beispiele anführen, so z. B. das Verhalten bei Papilio, bei Leptogaster, das Fehlen des Empodiums bei Midas u. s. w.

Wenn wir uns nun zum Schluss über die Bedeutung des Praetarsus selbst ein Urtheil bilden wollen, so scheint es mir 
zunächst nöthig, darauf hinzuweisen, dass diese Abtheilung alle Kennzeichen besitzt, welche für seine Auffassung als besonderes Glied nöthig erscheinen. Es ist sowohl unten wie oben durch Gelenke mit dem vorangehenden Abschnitt verbunden, besitzt auch eine besondere, in ihm endigende Sehne, während doch durch die mittlern Tarsalglieder nur dieselbe Sehne ihren Weg nimmt. Wie aus Fig. 111 von Asilus folgt, hat das ventrale Gelenk oft eine in die Augen fallende Uebereinstimmung mit den entsprechenden Gelenken der Tarsalglieder unter einander. Nur ist der Praetarsus an der Ventralseite oft weit in das letzte Tarsalglied zurückgezogen.

Der Praetarsus besteht nicht bloss aus Haftläppchen oder Krallen, den Hauptbestandtheil bildet die mediane Partie, welche am Ende das Empodium (oft als Haftlappen entwickelt) trägt und oberseits als unmittelbare Fortsätze die zwei Krallen. Es giebt an dieser Medianpartie auch zwischen der Krallenwurzel eine dorsale Fläche, welche namentlich bei Hymenopteren stark entwickelt sein kann. Hier, aber auch schon bei Hemipteren und Lepidopteren, trägt sie bisweilen sehr starke Borsten. In besonderer Richtung hat sich diese Fläche bei einigen Hymenopteren weiter entwickelt, wo dieselbe eine horizontal distalwärts vorspringende Querfalte aufweist, welche als „Schutzplatte" für die Krallen fungirt. Wenn wir also im Praetarsus ein besonderes Glied unterscheiden, so weichen wir doch von HuXley u. A. darin ab, dass wir als solche nicht hauptsächlich den Haftlappen betrachten, denn letzterer bildet nur einen unbedeutenden Anhang desselben, und auch ohne Haftlappen ist der Praetarsus ebenso sehr kenntlich.

Nachdem wir also festgestellt haben, dass es sich um ein besonderes Glied handelt, thut sich die Frage auf, ob die Bezeichnung als 6. Tarsalglied zutreffend sei. Es würde dies zu vertheidigen sein, wenn die Theilung des Tarsus in verschiedene Abschnitte zugleich auch zur Bildung des Praetarsus geführt hätte. Dafür fehlen aber die Gründe. Es zeigt sich vielmehr der Praetarsus als etwas Primitives der Tarsustheilung gegenüber. Bei vielen Arachniden und mehreren Insecten ist der Tarsus überhaupt ungetheilt, dennoch der Praetarsus ganz normal vorhanden. Man vergleiche als Beispiel Pediculus mit eingliedrigem Tarsus.

Dazu kommt, dass auch bei den Crustaceen der Dactylopodit den übrigen Gliedern sich als gleichwerthig gegenüber stellt und sich nicht bloss als letzten Abschnitt einer in mehrere Theile secundär gegliederten Beinpartie auffassen lässt. Dasselbe zeigt auch das grosse Endglied der 
Pycnogoniden, und auch bei Peripatus scheint mir die 2. Abtheilung der Extremität dem Praetarsus zu entsprechen, während alle die übrigen Beinabschnitte noch in der proximalen Abtheilung vereinigt sind. Es stellt sich somit der Praetarsus als ein Abschnitt höherer Ordnung dar als wenigstens die verschiedenen Tarsalglieder; darum scheint mir der Name 6. Tarsalglied nicht zutreffend.

Man muss sich doch vorstellen, dass die verschiedenen Glieder der Arthropodenextremitäten nicht gleichwerthig sind. Nachdem sich einmal einige Abschnitte gebildet hatten, welche sich auf die Nachkommen regelmässig vererbten, war in diesen Abschnitten secundäre Gliederung möglich. Zur Zeit ist es aber öfters noch unmöglich, die Natur jeder Gliederung richtig zu würdigen, weil hierfür umfassende vergleichende Untersuchungen nöthig sind, welche noch nicht vorliegen, aber doch lassen sich einige Beweise für secundäre Gliederung anführen. Als solche betrachte ich zunächst die Theilung des Tarsus der Insecten und Arachnoiden überhaupt. Bei vielen Insecten kommt noch ein ungetheilter Tarsus vor, bei andern finden sich 2, 3 oder 4 Glieder. Es mögen nun in einigen Fällen Glieder rückgebildet sein, dies scheint mir aber für viele dieser Fälle nicht wahrscheinlich, so z. B. für die eingliedrigen Füsse einiger Thysanura und der Collembola, eben so wenig wie für die zwei- oder dreigliedrigen Tarsen anderer Thysanura. Auch bei vielen Insectenlarven findet sich ein eingliedriger Tarsus, während das vollkommne Insect dieser Glieder mehrere besitzt. So theilt z. B. Sсносн ${ }^{1}$ ) mit, dass man in dem einzigen langen Fussglied der Nymphe von Ephemerella ignita PODA deutlich 5 Imaginal-Fussglieder eingeschachtelt sieht.

Auch der vielgliedrige Tarsus der Myriopodenabtheilung Cermatiidae $^{2}$ ) und die eigenthümliche Bildung des 2. Thorakalbeins bei Nika edulis RIsso ${ }^{3}$ ), welches aus einer grossen Reibe kurzer Glieder besteht, dürften durch secundäre Gliederung verursacht sein.

Bei den Arachnoiden kommt secundäre Gliederung, ausser am Tarsus (mehrere Füsse von Pedipalpen, Phalangiden), auch an andern Beinabschnitten vor. So sind z. B. nach Laurie ${ }^{4}$ ) bei den Pedipalpi

1) Eine pädogenetische Eintagsfliege, in: Mitth. Schweiz. entom. Ges., V. 7, 1887, p. 49.

2) Newport, in: Transact. Linn. Soc. London, V. 19, p. 284.

3) Milne-Edwards, Leçons sur la physiologie et l'anatomie comparée, V. 10 , p. 222.

4) Morphology of the Pedipalpi, in: Journ. Linn. Soc. London, V. 25,1896, p. 37. 
am 3. Gliedmaassenpaar die 2 (Phrynus) oder 3 (Telyphonus) letzten Glieder „secondarily segmented“. Weitere Beispiele finden sich ebendaselbst. Doch herrschen hier über die Zugehörigkeit der verschiedenen Beinabschnitte noch sehr aus einander gehende Ansichten.

Bisweilen lassen sich selbst tertiäre Gliederungen nachweisen, wie z. B. am Metatarsus von Nycteribiiden, welcher relativ lange Abschnitt hier eine grössere Anzahl Querringe zeigt, die durch dünnere Membran mit einander verbunden sind. Es ist hierbei aber noch nicht zur Bildung eigentlicher Gelenke gekommen.

Aus Obigem folgt, dass ich auch der Ansicht von MilneEDwards, welcher die Krallen als Homologa der Dactylopoditen auffasst, nicht ganz beistimmen kann. Wenngleich dieselbe in den Fällen, wo nur eine einzige Kralle vorhanden ist, welche alsdann beinahe den ganzen Praetarsus bildet, so ziemlich mit der meinigen übereinstimmt, so lassen sich doch die zwei Krallen des zweikralligen Insectenfusses nicht einfach mit zwei Dactylopoditen vergleichen, sondern sie bilden zusammen mit der Medianpartie und eventuell mit dem Empodium u. s. w. zusammen ein besonderes Glied, welches im Ganzen wohl einem Dactylopoditen homolog sein mag.

A msterdam, Juli 1900.

\section{Nachtrag.}

Während der Drucklegung dieser Arbeit erschien von der Hand J. J. KiefFeR's ein Aufsatz über die Krallen und die Haftläppchen der Dipteren ${ }^{1}$ ), welche ich hier in Kurzem besprechen möchte. In demselben handelt es sich zunächst um die verschiedenen Krallenformen der Dipteren; viele Beispiele von ungleichen Krallen, gezähnten oder gesägten, gespaltenen und kammförmigen Krallen werden aufgeführt. Ich möchte hierzu noch bemerken, dass auch nach meiner Erfahrung die beiden Krallen von Lipoptera cervi L. an den Vorderund Mittelbeinen ungleich sind. An diesen Beinen ist je die innere (vordere) Kralle die grösste, dagegen ist das bezügliche Haftläppchen klein, viel kleiner als das äussere (hintere), welch letzteres sich also an der Seite der kleinern Kralle befindet. An den Hinterfüssen sind die Haftläppchen in derselben Weise ungleich gross, in den Krallen

1) Illustr. Zeitschr. Entom., V. 5, No. 22, p. 337-340. 
aber befindet sich da kein bedeutender Unterschied. Beide Geschlechter verhalten sich in diesen Hinsichten gleich.

Während mir zur Zeit meiner Hauptuntersuchung Braula coeca Nitzsch nicht zur Verfügung stand, habe ich jetzt auch das eigenthümliche Fussende dieser Art aus eigner Beobachtung kennen gelernt. Die beiden besonders stark kammförmig eingeschnittenen Krallen sind doch wohl nicht so ganz mit einander verwachsen, wie KIEFFER es in fig. 5 und 6 abbildet. Sie berühren sich wohl in der Medianlinie des Praetarsus fast unmittelbar, besitzen aber doch lateralwärts von dieser Stelle je einen kleinen Gelenkhöcker; diese beiden Höcker sind $28 \mu$ von einander entfernt, während der quer abgestutzte Vorderrand des letzten Tarsengliedes $200 \mu$ lang ist. Bei den meisten Insecten liegen die zwei Krallen einander mehr oder weniger parallel; bei Braula dagegen sind ihre Spitzen so weit aus einander gerückt, dass die Längsaxe der beiden Krallen fast eine gerade Linie bildet, wie es auch KIEFFer und früher schon MeInert ${ }^{1}$ ) beobachtet hat. Wohl im Anschluss an diese eigenthümliche Lage sind die beiden Haftläppchen, welche hier nur winzige, spatelförmige Plättchen bilden, nach oben gerückt und liegen hier oberhalb der Krallen, unterhalb welcher auch überhaupt wegen der nach unten umgebogenen Kammzähne kein Platz für dieselben übrig ist. Diese auch von KIEFFER richtig abgebildeten Eigenthümlichkeit habe ich bei keinem andern Insect angetroffen. Ein Empodium oder Sohlenläppchen findet sich bei Braula nicht. Dass ausser Mochlonyx auch schon die Culex-Männchen an den vordern Beinen gezähnte und überdies ungleiche Krallen besitzen, blieb KIEFFER wohl unbekannt.

Was das „Empodium" (unser „Sohlenläppchen, resp. -fortsatz") anlangt, so scheint mir KIEFFER nicht genau den Unterschied zwischen einer Borste und einem borstenähnlichen Fortsatz ins Auge zu fassen. Für das betreffende Organ der Asiliden trifft wohl letztere Bezeichnung zu, es ist aber keine „Borste“ im morphologischen Sinn.

Nach meiner Erfahrung hat auch Chironomus flexilis L. 2 Haftläppchen und zwischen denselben einen kammförmigen Sohlenfortsatz, wie Kieffer es von $C h$. tentans F. und viridis Macq. angiebt. Dasselbe Verhalten finde ich z. B. auch bei Orthocladius thoracicus, während KiEFFER diese Gattung unter den ein „haftballenartiges Empodium" besitzenden Dipteren anführt.

Dass mir bei meinen Untersuchungen interessante Fälle entgangen

1) Aenigmatias blattoides Mern., in: Entom. Meddel., 1890. 
sind, geht schon aus dem Verhalten von Teichomyza fusca MAcQ. hervor. Die Haftläppchen sind bei dieser Art jederseits sehr tief fiederförmig eingeschnitten, so dass in der Mitte nur ein ganz schmaler Streifen (Breite $12 \mu$; das ganze Läppchen ist ca. $150 \mu$ lang) übrig bleibt. Jeder der ca. 10 Randfranzen ist wieder einerseits geweihartig eingeschnitten und ähnelt also dem kammförmigen Sohlenfortsatz von Dolichopus z. B. Das Ende dieser je 5 feinsten haarähnlichen Aeste ist mehr oder weniger kolbenartig erweitert; es werden durch dieselben wohl die Hafthaare repräsentirt. Diese Haftläppchen sind im Ganzen noch bedeutend zierlicher, als KIEFFER's Abbildung vermuthen lässt.

Bei Homalomyia canicularis L. fand ich den Sohlenfortsatz doch besser entwickelt als bei $H$. fucivorax KIEFF., obschon viel kürzer als die Seitenläppchen; er tritt hier in der Form eines scharfspitzigen, borstenähnlichen Gebildes auf, welches sich dicht unterhalb der Spitze plötzlich verjüngt; dasselbe ist jederseits gefiedert; alle Aeste sind ungefähr gleich lang und besitzen auch eine sehr scharfe Spitze. Wohl nur aus Versehen wird Meigen als Autor der von mir beschriebenen Monardia vanderwulpi angeführt. 


\section{Erklärung der Abbildungen.}

$\mathrm{Tafel} 30-37$.

Wo nichts anders angegeben, beziehen sich die Figuren auf
Praetarsus.
$\begin{array}{ll}\text { In den Figuren bedeutet: } \\ T E \text { Ende des Tarsus } & S l \text { Seitenlappen } \\ G h \text { Gelenkhöcker } & K l \text { Krallenläppchen } \\ K \text { Kralle } & S l l \text { Sohlenläppchen, bez. Sohlenborste } \\ S p \text { Streckplatte } & S \text { Sehne } \\ S s \text { Strecksohle } & O s \text { obere Sehne } \\ G f \text { Gleitfläche } & \text { Us untere Sehne } \\ E \text { Empodium } & D r \text { Druckborsten. } \\ H l \text { Haftlappen } & \end{array}$

Tafel 30 .

Fig. 1. Lepisma saccharina L. Seitliche Ansicht des Praetarsus. Fig. 2. " " " Untere Ansicht.

Fig. 3. Campodea staphylinus Westw. Seitenansicht. Sa seitlicher Anhang des Praetarsus, $M$ obere Medianlinie desselben.

Fig. 4. Isotoma. Praetarsus von der Aussenseite.

Fig. 5. " Derselbe von der Innenseite. $\boldsymbol{M h}$ Höcker in der Medianfläche, $\boldsymbol{F}$ Falte, $\boldsymbol{K} \boldsymbol{h}$ Kolbenhaar am Ende des Tarsus.

Fig. 6. Isotoma. Derselbe von unten. $M h$ Medianhöcker.

Fig. 7. Sminthurus. Seitenansicht. $M h$ medianer Höcker.

Fig. 8. Heptagenia elegans. Seitenansicht.

Fig. 9. Pyrrhosoma minium HARr. Seitenansicht.

Fig. 10. Nemura variegata OL. Praetarsus schief von unten.

Fig. 11. Periplaneta americana L. Untere Ansicht.

Fig. 12. Haftlappen $H l$ ist das Empodium. 
Fig. 13. Psocus. Seitenansicht. Hh Hafthaar, Sa seitlicher Anhang am Praetarsus.

Fig. 14. Psocus. Derselbe schief von unten.

Fig. 15. Carpocoris baccarum F. G. $K$ Gelenk zwischen Kralle und Krallenläppchen.

Fig. 16. Pyrrhocoris apterus L. Untere Ansicht.

Fig. 17. Calocoris bipunctatus L. Dreieckiges Haar am Ende der Strecksohle.

Fig. 18. Cyllocoris histrionicus L. Seitenansicht des Praetarsus; die Kralle fast losgelöst. Med dorsale Medianlinie des Praetarsus, $U$ das plattenförmige Haar am Ende der Strecksohle.

Fig. 19. Harpactor iracundus Scop. Seitenansicht. Die eine Kralle ist fast gelöst und nach oben umgelegt. Med dorsale Medianlinie des Praetarsus.

Fig. 20. Naucoris cimicoides L. Praetarsus des Mittelbeines von der Seite.

Fig. 21. Tettigonia viridis L. Seitenansicht.

Fig. 22. " " " Untere Ansicht.

Fig. 23. " " " Obere Ansicht. Ch stärker chitinisirte, borstentragende Stellen.

\section{Tafel 31 .}

Fig. 24. Pediculus vestimenti Burm. Sch Schiene, $\operatorname{Tr}$ Trachea. Fig. 25. Sialis lutaria L. Untere Ansicht.

Fig. 26. Chrysopa. Obere Ansicht.

Fig. 27. $\quad$ Untere Ansicht. Ch Chitinstreifen.

Fig. 28. Hemerobius. Praetarsus von unten. Der durchschimmernde Gelenkhöcker $(G h)$ ist mit eingezeichnet worden.

Fig. 29. Mantispa pusilla Er. Untere Ansicht.

Fig. 30. Myrmeleon frontalis WALK. Seitenansicht.

Fig. 31. Ascalophus longicornis L. Praetarsus von unten.

Fig. 32. Panorpa communis L, Ch stärker chitinisirte Stellen.

Fig. 33. Phryganea grandis L. Ch stärker chitinisirte Streifen.

Fig. 34. Larve von Limnophilus.

Fig. 35. Larve von Enoicula pusilla Burм.

Fig. 36. Papilio deiphobus L. Untere Ansicht.

Fig. 37. Eurrhypara urticata L. Praetarsus von der Seite. $B$ die den Lepidopteren eigenthümliche mediane Borste.

Fig. 38. Aciptilia xanthodactyla Tr. $B$ mediane Borste. Die Seitenläppchen $(S l)$ zeigen hier oben einen jederseits gezähnten Anhang.

Fig. 39. Luperina monoglypha HFn. Seitenläppchen.

Fig. 40.

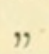

Krw Krallenwurzel.

Tafel 32 .

Fig. 41. Luperina monoglypha HFN. Medianer Längsschnitt des Praetarsus. $B$ mediane Borste. 
Fig. 42. Pyrameis cardui L. Untere Ansicht.

Fig. 43. Raupe von Euchelia jacobaeae L. Ende des Beines.

Fig. 44. Protocerius colossus OL. Von unten. TE Tarsenendglied, welches oben und unten den Praetarsus umklammert.

Fig. 45. Ptenidium evanescens Marsh. Seitenansicht.

Fig. 46. Hoplia coerulea Drur. Seitenansicht des Praetarsus vom Vorderbein.

Fig. 47. Dasytes plumbeus Müll. Von der Seite. $B$ Borsten am Ende des Empodiums.

Fig. 48. Psilothrix nobilis Grur. Untere Ansicht. $H l$ die in einen Haftlappen umgewandelte Kralle.

Fig. 49. Meloe proscarabaeus L.

Fig. 50. Iletica.

Fig. 51. Sitona lineatus L. Praetarsus schief von unten. $B$ breite Borsten an den Krallen.

Fig. 52. Larve von Dytiscus.

Fig. 53. Anoplus plantaris NaEz. Ende des Beines.

Fig. 54. Bembex rostrata L. Obere Ansicht. Stp Stützplatte.

Fig. 55. Pompilus. Obere Ansicht. Schp Schutzplatte.

Fig. 56. $" \quad$ Die Stützplatte von unten. $a$ vordere Partie derselben, o Oeffnung, welche in die Höhle der Stützplatte führt, Schp Schutzplatte.

Fig. 57. Pompilus. Medianer Längsschnitt des Praetarsus. $a$ vordere Partie der Stützplatte, Schp Schutzplatte.

Fig. 58. Vespa. Medianer Längsschnitt.

Fig. 59. Bombus. Untere Ansicht. Der kleine Haftlappen ist nach oben umgeschlagen, also unsichtbar.

Fig. 60. Pulex irritans L. Beinende von unten.

Fig. 61. Ctenophora flaveolata F. Seitenansicht.

Fig. 62. " " " Praetarsus von unten.

Fig. 63. " " " Medianer Längsschnitt des

Beinendes.

Fig. 64. Cylindrotoma distinctissima Meig. Seitenansicht.

Fig. 65. Pedicia rivosa L. Untere Ansicht.

Fig. 66. " " " Von der Seite.

\section{Tafel 33 .}

Fig. 67. Pedicia rivosa L. Von oben.

Fig. 68. Trichocera regelationis L. Praetarsus schief von unten.

Fig. 69. Amalopis tipulina EGg. Praetarsus von der Seite; die eine Kralle ist entfernt.

Fig. 70. Limnobia quadrinotata Meig. Untere Ansicht.

Fig. 71. Ptychoptera albimana F. Von oben.

Fig. 72. " " " Von der Seite.

Fig. 73. " " Von unten.

Fig. 74. Mycetophila. Seitenansicht. 
Fig. 75. Mycetophila. Von unten. $B$ Borsten am obern Ende des letzten Tarsalgliedes.

Fig. 76. Sciara thomae L. Von unten.

Fig. 77. Cecidomyia rosaria Löw. Von unten.

Fig. 78. Ceratopogon rostratus Winn. Von der Seite.

Fig. 79 .

Fig. 80 .

Fig. 81.

Fig. 82.

pulicaris L. "Von unten. pavidus Winn. Seitenansicht.

Fig. 84 . Seite.

Fig. 85. " rufipes L. Untere Ansicht.

Fig. 86. Metriocnemus albolineatus Meig. Von der Seite.

Fig. 87. Tanypus nervosus Meig. Von der Seite.

Fig. 88. Culex pipiens L. Ende des männlichen Vorderfusses, Seitenansicht.

Fig. 89. Seitenansicht.

Fig. 90. " annulatus Schrank. Ende des männlichen Vorderfusses, Seitenansicht.

Fig. 91. Culex annulatus Schrank. Ende des männlichen Hinterfusses, Seitenansicht.

Fig. 92. Corethra plumicornis F. Vorderfuss des Männchens, Seitenansicht.

Fig. 93. Dixa nigra Stakg. Von der Seite. $B A$ borstenförmiger Anhang der Kralle.

Fig. 94. Psychoda sexpunctata Cunt. Untere Ansicht.

Fig. 95. " " " Obere Ansicht.

Fig. 96. " $" \quad " \quad$ Von der Seite.

Fig. 97. Simulia maculata Meig. von unten. anhang.

Fig. 98. " pictipes $\mathrm{H}_{\mathrm{AG}}$. Obere Ansicht. $K A$ Krallen-

Fig. 99. " " " Von unten. KA Krallenanhang.

Fig. 100. " " " Kralle mit Anhang, von oben.

\section{Tafel 34 .}

Fig. 101. Simulia pictipes HAG. Halber Praetarsus, von unten.

Fig. 102. " " Kralle mit Anhang, von unten.

Fig. 103. Scatopse notata L." Untere Ansicht.

Fig. 104. Aspistes berolinensis MeIG. Untere Ansicht.

Fig. 105. Dilophus vulgaris Meig. Untere Ansicht.

Fig. 106. Rhyphus fenestralis Scop. Untere Ansicht.

Fig. 107. Stratiomyia furcata F. Medianer Längsschnitt durch den Praetarsus. Hy Hypodermis.

Fig. 108. Stratiomyia furcata F. Oberes Ende des letzten Tarsengliedes und Gelenkhöcker von vorn. 
Fig. 109. Stratiomyia furcata F. Querschnitt durch das Fussende, gerade vor dem letzten Tarsenglied.

Fig. 110. Tabanus bromius L. Fussende von unten.

Fig. 111. Asilus crabroniformis L. Medianer Längsschnitt durch das Ende des Fusses.

Fig. 112. Asilus crabroniformis L. Längsschnitt durch das Ende des Fusses. Hy Hypodermis.

Fig. 113. Asilus crabroniformis L. Längsschnitt seitwärts von der Medianfläche.

Fig. 114.

Chitinstreifen.

Fig. 115. " " Querschnitt in der Höhe der Linie $a b$ (Fig. 112). Hy Hypodermis, $C^{\prime} h$ Chitinstreifen.

Fig. 116. Asilus crabroniformis L. Querschnitt in der Höhe der Linie $c d$ (Fig. 112). gliedern.

Fig. 117. Asilus crabroniformis L. Gelenk zwischen zwei Tarsal-

Fig. 118. Leptogaster cylindricus DE G. Seitenansicht.

Fig. 119. Scenopinus fenestralis L. Von unten.

Fig. 120. Dolichopus aeneus DE G. Seitenansicht.

Fig. 121. Cyrtoma spurium FaLL. Untere Ansicht.

Fig. 122. Empis tessellata F. Untere Ansicht.

Fig. 123. Lonchoptera lutea Panz. Untere Ansicht. $B$ Borste am obern Ende des letzten Tarsengliedes.

\section{Tafel 35 .}

Fig. 124. Platypeza fasciata F. Untere Ansicht.

Fig. 125. Pipunculus sylvaticus Meig. Untere Ansicht.

Fig. 126. Phora. Seitenansicht.

Fig. 127. Eristalis tenax L. Medianer Längsschnitt.

Fig. 128. " " Längsschnitt seitwärts von der Medianfläche.

Fig. 129. Sicus ferrugineus L. Untere Ansicht.

Fig. 130. Chlorops didyma Zетт. Sohlenfortsatz, $a$ von der Seite, $b$ von unten.

Fig. 131. Scatella stagnalis Fall. Obere Ansicht.

Fig. 132. Ornithomyia avicularia L. Praetarsus von unten.

Fig. 133. Cyclopodia horsfieldi de Meijere. Seitenansicht; Praetarsus vorgestreckt.

Fig. 134. geschlagen.

Fig. 135.

Fig. 136. Scolopendrella. Seitenansicht.

Fig. 137. Lithobius forficatus L. Seitenansicht.

Fig. 138. Euscorpius italicus Herbst. Seitenansicht. 
Fig. 139. Euscorpius italicus Herbst. Ende des Tarsus und Chitinring an der Basis des Praetarsus, letzterer von hinten gesehen.

Fig. 140. Thelyphonus. Medianer Längsschnitt durch den Praetarsus. Hy Hypodermis.

Fig. 141. Thelyphonus. Seitenansicht.

Fig. 142. Argyroneta aquatica. Seitenansicht des Fussendes.

Fig. 143. Argyroneta aquatica. Seitenansicht des Praetarsus.

\section{Tafel 36 .}

Fig. 144. Thomisus. Seitenansicht.

Fig. 145. Attus. Seitenansicht. Die eine Kralle ist an der Wurzel abgeschnitten.

Fig. 146. Mygale avicularia L. Med dorsale Medianlinie des Praetarsus.

Fig. 147. Epeira diadema L. Ende des weiblichen Kiefertasters.

Fig. 148. " " Praetarsus und daneben einige "Vorkrallen".

Fig. 149. Phalangium. Seitenansicht.

Fig. 150. Chelifer. Seitenansicht. Ch Chitinhalbring.

Fig. 151. Hydrachna. Seitenansicht.

Fig. 152. Trombidium. Untere Ansicht.

Fig. 153. Ixodes reduvius L. (nympha III). Seitenansicht.

Fig. 154. Parositus cornutus CAN.

Fig. 155. Holostaspis marginatus Herm. (tritonympha heteromorpha o). Von oben.

Fig. 156. Solpuga. Seitenansicht.

Fig. 157. " Untere Ansicht.

Fig. 158. " Gelenk an der Spitze der Krallen. Gh' Gelenkhöcker, $S^{i}$ Sehne.

Fig. 159. Idotea. $\mathrm{Pr}$ proximaler, $D i$ distaler Theil des letzten Beinabschnittes.

Fig. 160. Idotea. Seitenansicht des Fussendes.

Fig. 161. " Medianer Durchschnitt des Fussendes.

Fig. 162. " Längsschnitt des Gelenks zwischen den zwei letzten Beinabschnitten.

Fig. 163. Sphaeroma. Endhälfte des letzten Beinabschnitts. schnitts.

Fig. 164. Asellus aquaticus L. Endhälfte des letzten Beinab-

\section{T afel 37.}

Fig. 165. Jaera albifrons Mont. Ende des Beines. $B l$ blattförmiger Fortsatz am Ende des vorletzten Beingliedes.

Fig. 166. Jaera albifrons Mont. Dasselbe von der andern Seite.

Fig. 167. Gammarus. Endhälfte des letzten Beinabschnitts.

Fig. 168. Nymphon grossipes. Längsschnitt durch das Gelenk zwischen dem letzten und vorletzten Beinglied. 
Fig. 169. Nymphon grossipes. Oberer Theil der Wurzel des Praetarsus.

Fig. 170. Nymphon grossipes. Aeussere Ansicht des Gelenks an der Basis des Praetarsus.

Fig. 171. Peripatus. Obere Ansicht des Fusses.

Fig. 172. $" \quad$ Derselbe von der Seite.

Fig. 173. " Derselbe von unten.

Fig. 174. $\quad$ Längsschnitte desselben. Hy Hypodermis, $M e d$ dorsale Medianlinie zwischen den Krallen, $M$ Rückziehmuskel. 


\section{$2 \mathrm{BHL}$ Biodiversity Heritage Library}

Meijere, J. C. H. de. 1901. "Ueber das letzte Glied der Beine bei den Arthropoden." Zoologische Jahrbücher. Abteilung für Anatomie und Ontogenie der Tiere 14, 417-476. https://doi.org/10.5962/bhl.part.10668.

View This Item Online: https://www.biodiversitylibrary.org/item/42717

DOI: https://doi.org/10.5962/bhl.part.10668

Permalink: https://www.biodiversitylibrary.org/partpdf/10668

\section{Holding Institution}

MBLWHOI Library

\section{Sponsored by}

MBLWHOI Library

\section{Copyright \& Reuse}

Copyright Status: NOT_IN_COPYRIGHT

This document was created from content at the Biodiversity Heritage Library, the world's largest open access digital library for biodiversity literature and archives. Visit BHL at https://www.biodiversitylibrary.org. 